Tjalling C. Koopmans Research Institute Tplligh Aoopman

Discussion Paper Series nr: 05-16

\title{
Evaluating the German Bank Merger Wave
}

Michael Koetter 


\title{
Tjalling C. Koopmans Research Institute Utrecht School of Economics \\ Utrecht University
}

Vredenburg 138

3511 BG Utrecht

The Netherlands

telephone $\quad+31302539800$

fax $\quad+31302537373$

website www.koopmansinstitute.uu.nl

The Tjalling C. Koopmans Institute is the research institute and research school of Utrecht School of Economics.

It was founded in 2003, and named after Professor Tjalling C. Koopmans, Dutch-born Nobel Prize laureate in economics of 1975.

In the discussion papers series the Koopmans Institute publishes results of ongoing research for early dissemination of research results, and to enhance discussion with colleagues.

Please send any comments and suggestions on the Koopmans institute, or this series to M.Damhuis@econ.uu.nl

ontwerp voorblad: WR IK Utrecht

\author{
How to reach the authors \\ Michael Koetter \\ The Boston Consolting Group \\ Fischertwiete 2 \\ G-20095 Hamburg \\ Germany \\ E-mail: koetter.michael@bcg.com \\ Utrecht University \\ Utrecht School of Economics \\ Vredenburg 138 \\ 3511 BG Utrecht \\ The Netherlands. \\ E-mail: m.koetter@econ.uu.nl
}

This paper can be downloaded at: http://www.koopmansinstitute.uu.nl 


\title{
Evaluating the German Bank Merger Wave
}

\author{
Michael Koetter \\ Boston Consulting Group \\ Hamburg \\ Utrecht School of Economics \\ Utrecht University
}

March 2005

\begin{abstract}
German banks experienced a merger wave throughout the 1990's. However, the success of bank mergers remains a continuous matter of debate.

In this paper we suggest a taxonomy as how to evaluate post-merger performance on the basis of cost efficiency (CE). We categorise mergers a success that fulfill simultaneously two criteria. First, merged institutes must exhibit CE levels above the average of non-merging banks. Second, banks must exhibit CE changes between merger and evaluation year above efficiency changes of non-merging banks. We employ this taxonomy to characterise (successful) mergers in terms of various key-performance and structural indicators and investigate the implications for four prominent policy issues particular to German banking. Our main conclusions are threefold. First, roughly every second merger is a success. Second, the margin of success is narrow, as the CE difference amounts to approximately 1 percentage point. Third, it takes around seven years after a transaction until maximum mean CE differentials materialise.
\end{abstract}

Keywords: Bank mergers, cost efficiency.

\section{Acknowledgements}

This paper is the result of a research cooperation between the Utrecht School of Economics and the Supervision department of the Deutsche Bundesbank. Helpful comments are acknowledged from Clemens Kool, Jaap Bos and participants of the 2004 NAKE day held at the Dutch central bank. I thank the Bundesbank for the permission to employ data and the Boston Consulting Group for financial support. All remaining errors are mine. 


\section{Introduction}

Time and again, practitioners and regulators claim that increased competition in the financial industry triggered profound changes in Germany's banking landscape. The drastic and continuous decline of the number of competitors since the early 1990s is one of the lighthouse cases put forward as an illustration of this claim. In fact, the number of banks constituting the three pillars of German banking declined from 4,177 to 2,160 between 1991 and 2003. ${ }^{1}$ Observers of the German banking landscape note that this consolidation is due to mergers and acquisitions rather than bank failures (Lang and Welzel (1998) and Porath (2004)).

Research on the dynamics of US banking markets is fairly abundant, but our knowledge of the effects of German bank mergers remains limited. This is cumbersome because bankers, regulators and the public all have an interest to evaluate the effects of bank mergers.

A clear understanding of post-merger performance can, for example, facilitate decision making of bankers on the one hand, and successful future supervisory work on the other. To our knowledge, this study is the first to analyse the consolidation effects of the merger wave among all German cooperative and savings banks. In this paper we suggest a taxonomy to evaluate bank mergers. The analytical workhorse in this paper is cost efficiency (CE) as measured by stochastic frontier analysis. We pursue three objectives. First, we want to identify successful mergers on the basis of CE. Second, we want to characterise successful as opposed to unsuccessful mergers. Third, we want to apply the taxonomy to evaluate the influence of potential skill transfers between merger partners, the success of mergers as a means of resolving distress, the impact of prevailing regulation on geographical limitations and learning effects from a transaction history for merger success. Thereby, we can draw inference on which future pairings are support-worthy versus those that should be opposed.

We organise the paper as follows. In section 2 we employ data provided by the Bundesbank to supply an extensive description of market dynamics in these two important bank pillars. This descriptive analysis serves as the fundament to section 3 where we formulate a set of questions to address four particularities in German banking. Section 4 explains the methodology for measuring CE and how we intend to identify successful mergers. In section 5 we present results on characteristics of merging and non-merging banks. We further investigate the effects of skill transfer, distress, regulation and learning on the success of mergers. We provide recommendations with regard to previously raised issues on the basis of fresh empirical evidence. Section 6 supplies some final thoughts.

\section{The German Bank Merger Wave}

Our starting point in this paper is a stylised fact - German banks merged. The literature on bank mergers suggest a variety of possible reasons for this observation. ${ }^{2}$

\footnotetext{
${ }^{1}$ The three pillars are commercial, savings and cooperative banks (Hackethal (2004)).

${ }^{2}$ For example, the OECD (2000) lists technical change, globalisation and deregulation as three major triggers for mergers in the financial industry.
} 
But as put forward by Amel et al. (2004), the majority of motives advocated are not mutually exclusive and thus rather reflect attempts to rationalise as to why banks merge instead of representing exclusive explanations.

This indeterminacy of merger motives notwithstanding, the causal chain of events is according to many scholars surprisingly similar (e.g. Berger (2003)). Decreased information asymmetries of investors, lower switching costs for borrowers, non-bank intermediaries venturing into traditional bank activities and more leeway for incumbent banks to expand operations both in terms of geographic and product scope all lead to increasing competitive pressure.

To counter these pressures, banks engage in mergers in order to utilise resources more efficiently. Likewise, a profound lack of efficient operations can lead banks to face financial distress. To resolve distress, banks may exit the market through mergers, some of which may actually be favoured by regulators or even induced by head organisations to ensure financial stability and soundness. ${ }^{3}$

Hence, the effects of mergers should ideally affect efficiency in a positive way. Therefore, many studies on merger effects focus on a comparison of the productive efficiency of banking firms. We follow this notion and provide in this section a description of the major characteristics accompanying the German merger wave.

\subsection{Competitive Pressure}

We have at our disposal data on all savings and cooperative banks for the period from 1993 until 2003. We focus on these two pillars for three reasons. First, they account for more than a third of total assets managed in the German banking system and represent more than 80 percent of all banks in terms of number. Second, the vast majority of mergers occurred among these institutes. While a number of studies focus on mergers among publicly listed banks, this study provides to our knowledge the only evidence on the (lack of) success of mergers for these banking sectors as a whole. Third, Hackethal (2004) points out that savings and cooperative banks are vital to the backbone of Germany's economy, namely the "Mittelstand". Therefore, we are particularly concerned about the effects of consolidation dynamics in these banking groups.

The data were obtained from the supervisory department of the Bundesbank. All banks operating in Germany annually report balance sheet and profit and loss account data. To grasp the dynamics of competitive pressure during the last decade, consider table 1.

Profitability as measured by return on equity (ROE) more than halved in this period. If competition increases, prices are driven down to marginal cost. As markets approach perfect competition, textbook economic theory predicts that no additional rents above marginal cost can be realised. We cannot observe marginal cost. But the development of ROE indicates in any case that comfortable profit bolsters during the early 1990s no longer prevail among German banks.

\footnotetext{
${ }^{3}$ While, for example, in the US the regulatory authorities occasionally close banks or order them merge, the German Bundesbank cannot intervene directly. A study by Koetter et al. (2004) on ex ante determinants of German bank mergers provides evidence that mergers frequently serve distress resolution efforts. They find that German cooperative and savings bank mergers are more likely if financial profiles deteriorate.
} 
Table 1: Key performance indicators German banking 1993-2003

\begin{tabular}{lccccc}
\hline Year & ROE $^{\mathbf{1}}$ & CI $^{\mathbf{2}}$ & NIM $^{\mathbf{3})}$ & HHI $^{\mathbf{4})}$ & Banks \\
\hline $\mathbf{1 9 9 3}$ & 19.5 & 70.6 & 3.2 & 2,976 & 3,464 \\
$\mathbf{1 9 9 4}$ & 15.7 & 67.1 & 3.3 & 3,080 & 3,305 \\
$\mathbf{1 9 9 5}$ & 18.3 & 69.6 & 3.1 & 3,142 & 3,203 \\
$\mathbf{1 9 9 6}$ & 16.5 & 70.2 & 3.1 & 3,199 & 3,103 \\
$\mathbf{1 9 9 7}$ & 14.5 & 70.5 & 3.0 & 3,263 & 3,004 \\
$\mathbf{1 9 9 8}$ & 12.2 & 72.6 & 2.7 & 3,350 & 2,833 \\
$\mathbf{1 9 9 9}$ & 10.9 & 73.6 & 2.7 & 3,514 & 2,597 \\
$\mathbf{2 0 0 0}$ & 9.3 & 74.2 & 2.7 & 3,656 & 2,347 \\
$\mathbf{2 0 0 1}$ & 7.3 & 75.8 & 2.6 & 3,788 & 2,147 \\
$\mathbf{2 0 0 2}$ & 7.9 & 72.8 & 2.7 & 3,967 & 1,999 \\
$\mathbf{2 0 0 3}$ & 9.3 & 71.6 & 2.8 & 4,110 & 1,868 \\
\hline Total & 13.6 & 71.4 & 2.9 & 3,389 & 29,870 \\
\hline 1) Return on Equity; ${ }^{2)}$ Cost-income ratio; ${ }^{3)}$ Net interest margin; \\
4) Hirschman-Herfindahl Index between 0 and 10,000 per county. \\
Note: ROE, CI and NIM in percent.
\end{tabular}

The fact that cost-income ratios (CI) stayed fairly constant in the course of events signals to us that the deterioration of profitability cannot be explained by poor bank management alone. In such a case, administrative expenses as a share of operative revenues should have soared in lock-step. However, with the exception of the period involving stock market crashes around the turn of the century, we observe that mean CI ratios seem to have been kept in check on an ongoing basis.

At the same time, deteriorating net interest margins (NIM) could reflect how spreads between lending and borrowing are competed away. Seemingly, ongoing consolidation, as illustrated by the declining number of banks, did not result in banks seeking monopoly rents. Individual cooperative and savings banks might still be too small to exercise market power. The mean size increased for our sample from around $€ 300 \mathrm{~m}$ to a still fairly small scale of operations of $€ 820 \mathrm{~m}$. We interpret our findings as indication that despite increasing mean size banks continued to face considerable competition. Consequently, excessive market power is at first sight a minor concern.

According to Koetter et al. (2004) not a single bank exited the market due to outright failure during the observation period. The consolidation nonetheless left a profound imprint on Germany's banking structure. Local market concentration increased by more than 25 percent. ${ }^{4}$ Measured by total assets under management per county and year we record an increase in the Hirschman-Herfindahl Index from just below 3,000 to 4,110 points between 1993 and 2003.

In sum, simple key performance indicators (KPI) convey that competitive pressures increased among German banks during the last decade despite increasing concentration. A massively reduced number of institutes bears witness to a changing bank market structure. The brunt of these changes is in fact borne by

\footnotetext{
${ }^{4}$ The benefits and limitations of simple concentration measures as proxies for competition are discussed e.g. in Hempell (2004). Note, that we do not attempt here a formal investigation of the causal relation between market power, concentration and prices. We rather restrict ourselves to simply acknowledge that market structure changed substantially in terms of markedly fewer banks managing increasingly larger volumes of assets.
} 
mergers, as we show in the next sub-section. The massive reduction of the number of banks demands an evaluation of the success of mergers and the implications for the industry in a more detailed fashion rather than simply examining aggregate measures for the whole industry.

\subsection{Consolidation}

The Bundesbank collected data on 1,417 targets that were acquired during the period from 1994 to $2002 .{ }^{5}$ We have information about both acquirer and target at our disposal for each of these transactions. ${ }^{6}$ Table 2 provides data on the mean size of acquiring, target and non-merging banks in the year prior to the merger. We depict these measures by banking group. Additionally, we supply both the total volume and the number of acquirer and targets.

Table 2: Size and number of mergers per sector

Savings banks

\begin{tabular}{|c|c|c|c|c|c|c|c|}
\hline Merger year & Acquirer $^{1)}$ & Targets $^{1)}$ & Non-merging $^{1)}$ & Total $T A^{2)}$ & & $N$ Acquirer $^{3)}$ & $N$ Target \\
\hline 1994 & 770 & 295 & 1,166 & 13,900 & & 36 & 47 \\
\hline 1995 & 504 & 317 & 1,253 & 9,200 & & 22 & 29 \\
\hline 1996 & 1,630 & 384 & 1,329 & 6,530 & & 13 & 17 \\
\hline 1997 & 1,660 & 764 & 1,411 & 6,120 & & 7 & 8 \\
\hline 1998 & 1,890 & 683 & 1,493 & 2,730 & & 4 & 4 \\
\hline 1999 & 1,320 & 576 & 1,585 & 8,640 & & 12 & 15 \\
\hline 2000 & 1,560 & 863 & 1,605 & 12,900 & & 13 & 15 \\
\hline 2001 & 2,090 & 743 & 1,651 & 17,800 & & 20 & 24 \\
\hline 2002 & 3,810 & 567 & 1,705 & 9,630 & & 16 & 17 \\
\hline Mean & 1,520 & 497 & 1,523 & 11,400 & Sum & 143 & 176 \\
\hline \multicolumn{8}{|c|}{ Cooperative banks } \\
\hline 1994 & 180 & 53 & 160 & 5,700 & & 104 & 108 \\
\hline 1995 & 209 & 65 & 173 & 4,380 & & 65 & 67 \\
\hline 1996 & 321 & 68 & 187 & 5,290 & & 72 & 78 \\
\hline 1997 & 382 & 79 & 200 & 6,590 & & 79 & 84 \\
\hline 1998 & 355 & 95 & 211 & 15,100 & & 141 & 159 \\
\hline 1999 & 427 & 134 & 224 & 28,000 & & 174 & 209 \\
\hline 2000 & 394 & 112 & 234 & 26,700 & & 202 & 238 \\
\hline 2001 & 384 & 115 & 239 & 19,400 & & 147 & 169 \\
\hline 2002 & 455 & 155 & 252 & 20,000 & & 114 & 129 \\
\hline Mean & 362 & 106 & 220 & 18,000 & Sum & 1,098 & 1,241 \\
\hline
\end{tabular}

In accordance with Lang and Welzel (1996), we observe that most mergers occurred among cooperative banks. While the number of German savings banks declined by approximately 20 percent from 654 banks in 1994 to 519 banks at year

\footnotetext{
${ }^{5}$ The total number of targets is 1,465 in the reference period, representing a decline from 3,464 institutes in 1993 to 1,999 institutes in 2002. We had to discard 48 mergers due to missing data on either the acquirer or the target. We lack information prior to 1994 and after 2002.

${ }^{6}$ The number of acquirers is below the number of targets due to, first, serial acquirers and, second, multiple acquisitions in a given year by the same acquirer.
} 
end of 2003, the corresponding decline of cooperative banks is 45 percent, reflecting a reduction in the number of banks from 2,651 to 1,480 in the same period. Consequently, the merger process in the two sectors might differ. For example, regulation and/or government ownership potentially shelters savings banks to a larger extent from competition compared to cooperatives. We then would expect market structure and profitability measures to exhibit these differences. We therefore investigate in the next subsection some simple performance and structural indicators per sector in the year of a merger.

Because we focus in this paper on an evaluation of the (lack of) success of bank mergers, we are less interested to add another, to put it in terms of Amel et al. (2004), rationalisation to the literature as to why banks merged. We limit ourselves to extend our set of KPI introduced in section 2.1 by three additional indicators. In doing so we aim to assess the plausibility of three frequently raised motives by simple characteristics per bank. Let us briefly discuss the three motives mentioned before we turn to the ratios in the next section.

A first reason as to why banks might merge is to enhance productivity of labour. An intuitive illustration of this motive relates to technical advances in banking. For example, Valverde et al. (2004) provide evidence that the increased use of automatic teller machines and electronic payment systems fostered the reduction of (labour intensive) branch offices. It is conceivable that banks aim to enhance the productivity of labour by means of mergers. As German labour laws are restrictive, restructuring the branching network of two banks operating with considerable overlap is easier compared to simply laying off employees and substituting them with technology.

Secondly, time and again practitioners hypothesise that merging banks aim to realise economies of scale. ${ }^{7}$ Table 2 illustrates the small size especially of cooperative banks. Cost pressures due to squeezed interest margins and too small operations to spread fixed costs fuel the (perceived) need to expand the asset base of these banks. The popularity of this notion among practitioners is vividly illustrated by a quote from Wolfgang Arnold, vice president of the German Bankers Association:

"[...] Ein alter ökonomischer Lehrsatz befasst sich mit den Economies of Scale. Wenn man erforderliche Größenordnung nicht selbst erreichen kann, schließt man sich zusammen und optimiert über die Volumina kostenträchtige Abläufe. [...]"8

While we point out that the academic literature fails consistently, somewhat stubbornly, to find evidence in favour of economies of scale, we devise below a simple indicator variable to learn if successful mergers exhibit characteristics that support this motive. ${ }^{9}$

\footnotetext{
${ }^{7}$ According to Amel et al. (2004) this is probably one of the most popular potential motives.

${ }^{8}$ Press conference held in Frankfurt am Main on September 18, 2002. Available at http://www.bdb.de. The unofficial translation is: "[...] An established economic proposition concerns economies of scale. If one cannot achieve the required size of operations individually, one combines these operations to optimise cost-intensive workflows by means of higher quantitities processed. [...]"

${ }^{9}$ Importantly, we do not claim here to conduct a formal investigation of the issue. European studies that focus on the estimation of (the lack of) economies of scale include Altunbas and Molyneux (1996) and Lang and Welzel (1996).
} 
For an illustration of a third popular motive, consider the number and volume of deals depicted in table 2. The second peak of merger activity around the turn of the century is associated with turmoil in security markets. ${ }^{10}$ Banks that expanded their securities business during rallying stock markets may have fallen victim to mergers after the stock market crashed. Struggling banks with relatively large non-interest income shares potentially turned prey to banks that aimed to diversify income sources at comparably favourable conditions. ${ }^{11}$

As noted throughout we do not assume that any of these rationales is solely "responsible" for mergers to occur. However, if these frequently encountered merger motives - scale, scope and efficiency enhancement - indeed drive mergers, we expect to observe that our simple descriptives reflect these goals and improve after a merger. At the same time, numerous academics point out that only half of all mergers are successful as far as value maximising objectives such as the ones mentioned previously, are concerned. For example, Schenk (2000) argues that the vast majority of mergers serve the objectives of managers instead of value maximisation.

While we do not attempt to provide an exhaustive analysis about the motives underlying mergers, we turn next to these characteristics across merging and nonmerging banks to obtain the stylised facts on bank characteristics after a merger.

\subsection{Characteristics}

If we assume that increased competition is indeed a major driving force of mergers and therefore changing market structures, we are interested in learning about the immediate implications for bank's post-merger profitability and costs. In table 3, we depict mean KPI to compare merging and non-merging banks across bank sectors in the year a deal occurred. ${ }^{12}$

Profitability differed significantly for both banking groups between merging and non-merging banks by 5 to 7 percentage points of ROE. Likewise, cost pressure is higher for banks that just merged, as measured by higher CI ratios. However, comparably poor KPI may result from a recent transaction, for example, due to the integration of a new sales force or from incurring additional advisor fees during the transaction.

Local concentration, measured by HHI, is higher among those banks that merged, especially for savings banks. Those banks that merged are thus operating in local markets with at times markedly fewer competitors. This can imply market power. But at the same time mean NIM do not differ a lot between merging and non-merging banks. Furthermore, for savings banks mean NIM is not significantly different. Also, despite substantially higher concentration among merging savings banks, mean NIM are virtually identical across banking groups. Rent seeking therefore seems to be an issue of less importance in our sample.

\footnotetext{
${ }^{10}$ After a period of rallying stock markets, the stock market index DAX tumbled from an annual average of 6,164 points in 1999 to 3,967 points in 2002.

${ }^{11}$ This motive indicator variable relates to the literature that seeks to estimate economies of scope. Examples of studies along this strand include Vander Vennet (1996), Lang and Welzel (1998) or Bos and Kolari (2003).

${ }^{12}$ This is in contrast to table 2, where mean KPIs refer to pre-merger years.
} 
Table 3: Mean characteristics of merging versus non-merging banks

\begin{tabular}{lrrrrrr} 
& \multicolumn{3}{c}{ Savings banks } & \multicolumn{3}{c}{ Cooperative banks } \\
\hline \multicolumn{1}{c}{ KPI } & Non & Merger & p-value & Non & Merger & p-value \\
\hline ROE & 15.6 & 8.4 & 0.000 & 13.7 & 8.7 & 0.000 \\
CI & 65.6 & 70.4 & 0.000 & 71.8 & 75.9 & 0.108 \\
NIM $^{1)}$ & 2.7 & 2.8 & 0.213 & 2.9 & 2.8 & 0.000 \\
HHI $^{2)}$ & 3,685 & 5,305 & 0.000 & 3,239 & 3,589 & 0.000 \\
Prod $^{3)}$ & 0.29 & 0.33 & 0.000 & 0.33 & 0.34 & 0.000 \\
UC $^{4)}$ & 5.8 & 5.7 & 0.755 & 6.0 & 6.1 & 0.001 \\
INC $^{5)}$ & 7.7 & 7.7 & 0.941 & 8.8 & 10.4 & 0.000 \\
\hline N & 4,294 & 143 & \multicolumn{5}{c}{8,508} & 1,098 \\
\hline 1) Net interest margin in percent; ${ }^{2)}$ Hirschmahn Herfindahl Index in points; \\
3) Productivity approximated as FTE per mn Euro of total assets; ${ }^{4)}$ Unit \\
cost in cents of total operating cost per Euro of total assets; ${ }^{5)}$ Income \\
structure as fee over total revenue in percent; ${ }^{6)}$ Test for equality of means \\
Note: Excluding pre-merger observations of ultimately merging banks.
\end{tabular}

But while we find only limited evidence for rent seeking, higher concentration may still imply that market discipline is lacking and therefore banks fail to monitor costs carefully. Foregone cost savings imply unnecessary reductions of producer surplus and are thus undesirable. This line of thought is supported by higher CI ratios for merging banks of both sectors, when paired with higher mean concentration.

In section 2.2 we collected three potential motives as to why banks merge. These are to enhance labour productivity, to reduce fixed costs relative to total assets and to diversify income sources. While we abstain from a formal investigation of these motives due to reasons mentioned above and in Amel et al. (2003), we devise three simple indicators to gain some insight.

To grasp the labour productivity of merging and non-merging banks, Prod, we relate the number of full time equivalent employees (FTE) per bank to total assets. While the difference in table 3 is small, we find that merging banks employ significantly more FTE per million Euro of total assets than non-merging banks. According to this rough measure, non-merging savings banks use labour most productively and merging cooperative banks need relatively high amounts of labour to produce their output.

To investigate if economies of scale are a plausible merger motive, we relate banks' operating costs to total assets to approximate unit costs, UC. Our data indicate that among small cooperative banks the difference between merging and non-merging banks is significant but small. For each Euro of total assets cooperative banks incur roughly 6 Euro cent in costs. Somewhat lower unit costs of savings banks are in line with larger mean sizes reported in table 2. But minuscule differences between merging and non-merging banks indicate that scale economies are not a primary reason behind mergers. ${ }^{13}$

A third potential motive is the notion that banks merge to diversify their income sources. We investigate whether fee income as a share of total revenue,

\footnotetext{
${ }^{13}$ While we are aware of the crudeness of our measure, this simple plausibility check is in line with the vast majority of studies that consistently fail to identify scale economies gains due to mergers.
} 
INC, differs significantly between merging and non-merging banks. While we reject the null hypothesis of different mean fee income shares for savings banks, we find evidence that merging cooperative banks exhibit an earnings structure significantly different from non-merging banks. The relatively large difference suggests that tapping alternative income sources could be a reason for (cooperative) bank mergers.

To sum, we find that merging and non-merging banks differ with respect to profitability and cost management both in the savings and cooperative banking sector. These KPI measures indicate that merging banks perform worse than non-merging ones in the transaction year. Regarding interest margins, market concentration, labour productivity, unit costs and income sources, we receive mixed signals depending on the banking sector. Merging savings bank operate in significantly higher concentrated local markets and suffer from lower labour productivity; merging cooperative banks exhibit a higher share of fee income. Regarding market concentration, differences between merging and non-merging banks are either minuscule and/or insignificant.

The described characteristics indicate that merging banks perform at best mediocre. But with regard to the evaluation of the success of mergers, we argue that all of the discussed measures suffer from two major limitations.

The first caveat refers to the development of KPI over time. For example, lower labour productivity in the transaction year itself may merely reflect the rigidity of German labour laws. Adjustments of the labour force are time-consuming as, for example, numerous employees at savings banks are protected by civil servant status. Hence, large scale labour force reduction is only possible by using natural fluctuation rather than Anglo-Saxon style lay-off waves. Therefore, it is in our view crucial to track the performance of merged institutes over some time.

The second caveat is that any of the above mentioned measures provide little information about what the optimal KPI could have been for banks operating under potentially markedly different circumstances. After all, the share of the difference between mean ROE for merging and non-merging banks that is attributable to poor management of the bank versus deteriorating economic conditions or sheer bad luck remains unclear. We simply cannot state by observing some increased post merger ROE whether the firm performed optimally - a higher return after the merger might still be far from what could have been attained. ${ }^{14}$

An alternative strand in the literature therefore suggests benchmarking banks according to their ability to convert inputs into outputs. ${ }^{15}$ We employ cost efficiency (CE) to measure the success of mergers. This approach ranks firms relative to an optimal industry cost function.

In our view the appeal of this measure is that we evaluate mergers on the basis of simple textbook microeconomic theory. We assume that banks operate on markets that are appropriately described by perfect competition (Bikker and Haaf (2002)). We expect a cost minimising firm to produce its' outputs by demanding required inputs subject to prevailing input prices. We can then estimate

\footnotetext{
${ }^{14}$ Additionally, profitability of publicly listed firms might offer an indication on the basis of (perfect) stock market return. Numerous studies investigate therefore the existence of abnormal returns to evaluate mergers. But stocks of banks of these two pillars are not traded and therefore so-called event studies are not an option to assess this merger wave.

${ }^{15}$ See for example Vander Vennet (1996), Peristiani (1997) and Lang and Welzel (1998).
} 
an optimal cost function under the assumption that deviations from best practice are, first, due to random noise and, second, due to inefficient allocation of inputs. Intuitively, no bank can incur systematically higher costs compared to competitors. To avoid being driven out of the market any bank has to demand inputs in optimal proportions to produce a given output vector. ${ }^{16}$

We postpone a formal introduction of our empirical model as to measure cost efficiency to section 4 . We focus beforehand on four possible explanations as to why some mergers in German banking are a success and others are not.

\section{Facilitators and Obstacles to M\&A Success}

The preceding subsection shows that we have to, first, distinguish between successful and unsuccessful mergers. Second, we are interested in the development of bank-specific characteristics as measured by the previously introduced KPI over time. As opposed to these bank-specific characteristics, merger success might crucially depend on characteristics related to both how the deal is conducted and the environment in which it takes place. We refer to these as deal-specific characteristics and we investigate the following four: ${ }^{17}$

1. Transfer of skills between merging banks

2. Mergers as distress resolution tool

3. Influence of regional demarcation

4. Presence of learning effects

With the exception of the influence of regional demarcation on merger success, we regard these deal characteristics as endogenous to merger management. That is, we assume that regulation cannot be influenced by the management in charge of conducting the merger. Rather, investigation of the relation between regional demarcation and merger success intends to shed light on the costs and benefits of this arrangement. In contrast, the latter three characteristics are the result of decisions made by management, i.e. if and how to transfer skills, to merge with another bank in order to resolve distress or to commit to a strategy of more than just one merger. In fact, our merger data allows us to classify mergers according to these four criteria and thus learn if deals with particular characteristics are more or less frequently a success (or a failure).

Subsequently, we motivate each of the four either by means of evidence from the literature or on the basis of merger data available. In addition to the development of merging banks' KPI, these four deal characteristics will serve later on as a guideline to structure the discussion of our results in section 5 .

\footnotetext{
${ }^{16}$ We argue that this also holds for banks which potentially pursue alternative objectives in the long run no firm can afford systematically higher costs for identical production factors employed.

${ }^{17}$ Clearly, there is a virtually infinite amount of both additional bank- and deal-specific factors that may matter. An example of the former is demographics on board composition, for the latter it is the macroeconomic environment. Our choice of KPI and deal-specific characteristics is motivated by the availability of data and the policy relevance of the deal characteristic from our point of view.
} 


\subsection{Transfer of Skills}

Lang and Welzel (1998) investigate merger effects for a sample restricted to cooperative banks in Bavaria. They find that in $53 \%$ of all mergers the acquirer is more cost efficient than the target. However, only $18 \%$ of all merged banks with higher ex ante acquirer CE managed to exhibit above average efficiency growth after the merger. In contrast, they find that $35 \%$ of all mergers with positive ex ante $\mathrm{CE}$ differences yield below average $\mathrm{CE}$ growth after the merger. They conclude that these acquirers failed to transfer their superior CE skills to the target.

This finding reflects that the transfer of cost management skills matters a lot to determine success but that it can be difficult to accomplish. ${ }^{18}$ If banks with superior CE performance manage to lift the merged units' overall CE, mergers are a desirable because they improve the competitive position of a bank and thereby strengthen the stability of the whole banking system. ${ }^{19}$

Whether a beneficial transfer of skill is successful depends on two major factors. First, the size of the ex ante differential. On the one hand, a larger differential can indicate that cost management skills of one of the partners are clearly below those of the other partner. Then, potential for improvement is easily identified. Relatively large gains may be quickly realised by simple imitation. An example is that one bank pursues excessive spending on real estate resulting in excessive office capacities. Switching to facilities closer to market cost then entails a quick win if switching costs are low enough. On the other hand, a large differential can indicate that one partner suffers from substantial problems that cannot be easily remedied. An example is a funding structure incurring too high interest payments. If these are stipulated in contracts there is presumably little a new management team can do in the short run.

The second factor refers to whether it is the target or the acquirer that exhibits higher CE. Acquirers that are dominant in terms of CE may very well command sufficient power to enforce their management procedures on the target. However, we have no reason to expect ex ante that the acquirer is indeed superior. Because of the respective government and member ownership structure of savings and cooperative banks, as described by Altunbas et al. (2001), we know that ownership shares are not freely traded. Consequently, majority stakes cannot be accumulated in a hostile fashion. The absence of a full-fledged market for corporate control may imply that objectives other than value maximisation are important for determining the acquirer and target in a merger. ${ }^{20}$ If it is indeed to some extent a political process that determines the role in a merger, it may turn out that a large but potentially less efficient bank is the acquirer. Then, it can be less likely that best practise from the target is wholeheartedly embraced by the new organisation.

Whether such scenarios prevail and whether we can observe particular combinations of pre-merger $\mathrm{CE}$ differentials to yield systematically more (or less)

\footnotetext{
${ }^{18}$ Consider as an intuitive example the integration of human resource (HR) departments. If former managers from both institutes shape new HR policies jointly these are likely to contain elements of both pre-merger policies.

${ }^{19}$ How far such joint CE must be lifted depends on the definition of a successful merger. We discuss that matter at length in the next subsection.

${ }^{20}$ Evidence provided by Koetter et al. (2004) rather indicates that it is largely size by which the role of a bank in a merger is stipulated.
} 
successful mergers remains an empirical question that we address below. This way, bankers, head organisations and regulators can evaluate pending mergers on the basis of pre-merger $\mathrm{CE}$ differentials to promote beneficial combinations that are likely to improve $\mathrm{CE}$.

\subsection{Mergers and Distress}

As mentioned before, no single bank went into outright bankruptcy during the observation period. Therefore, it is reasonable to expect that a number of bank mergers served the purpose to remedy distress. Table 4 underpins that around 100 transactions are evaluated by the Bundesbank as distressed.

Table 4: Distressed merger partners

\begin{tabular}{rrrrrr} 
Year & None & Target & Acquirer & Both & Total \\
\hline $\mathbf{1 9 9 4}$ & 155 & n.a. & n.a. & n.a. & 155 \\
$\mathbf{1 9 9 5}$ & 91 & 1 & 4 & 0 & 96 \\
$\mathbf{1 9 9 6}$ & 90 & 2 & 3 & 0 & 95 \\
$\mathbf{1 9 9 7}$ & 85 & 2 & 3 & 2 & 92 \\
$\mathbf{1 9 9 8}$ & 141 & 12 & 10 & 0 & 163 \\
$\mathbf{1 9 9 9}$ & 199 & 14 & 9 & 2 & 224 \\
$\mathbf{2 0 0 0}$ & 233 & 12 & 7 & 1 & 253 \\
$\mathbf{2 0 0 1}$ & 176 & 4 & 12 & 1 & 193 \\
$\mathbf{2 0 0 2}$ & 146 & n.a. & n.a. & n.a. & 146 \\
\hline Total & 1,316 & 47 & 48 & 6 & 1,417 \\
\hline
\end{tabular}

Note, that the Bundesbank does not order distressed banks to merge. In fact, the Bundesbank itself cannot even intervene directly. ${ }^{21}$ However, the Bundesbank conducts the daily supervision. Cooperative and savings banks' annual reports are assessed by auditors from the respective head organisations. ${ }^{22}$ Head organisations are therefore involved in the bank supervision process and one might regard them as intermediaries between regulators and banks. These audit reports represent an important input to central bank examiners. Based on their assessment of the bank, audit reports and accounting information directly submitted to the supervision department, the Bundesbank may evaluate a merger as distressed. ${ }^{23}$

It is imperative to note that the records of the Bundesbank on distressed mergers do not imply interventions by the Bundesbank or the BaFin. The record represents a "failure" according to the evaluation of the Bundesbank. It does not mean that either the Bundesbank or the BaFin forced two banks to merge. Instead, the observed merger is evaluated by bank examiners as a distressed merger. The actual decision to merge may in fact represent the bank's own decision to resolve distress or to follow suggestions of the respective head organisations.

\footnotetext{
${ }^{21}$ In Germany, only the Federal Institute for Financial Services Supervision ("Bundesanstalt für Finanzdienstleistungsaufsicht, BaFin") can issue legally binding interventions.

${ }^{22}$ For saving banks this is the German Savings and Giro Association ("Deutscher Sparkassenund Giroverband", DSGV) and for cooperative banks this is the Federal Association of Cooperative Banks ("Bundesverband der Deutschen Volksbanken und Raiffeisenbanken, BVR").

${ }^{23}$ The data assigns the distress status either to the target, the acquirer or both parties involved in the merger.
} 
In sum, our data permit identification of mergers that received regulatory attention due to distress as opposed to transactions involving banks that were not evaluated by the Bundesbank records as distressed merger. ${ }^{24}$

As can be seen in table 4, the records of the Bundesbank on distressed events are not limited to cases where a bank becomes a target. In fact, it occurred equally often that distress resulted in the bank acquiring a non-distressed bank. Only in six cases, both parties involved in the merger were identified as distressed by the Bundesbank.

We want to examine if mergers are a successful instrument to ensure financial stability and soundness. To this end, we analyse below if distressed mergers are relatively more or less frequently identified as a success.

\subsection{Mergers and the Principle of Regional Demarcation}

While supervision authorities adhere to principles of financial soundness and stability, representatives of these head organisations, the $D S G V$ and $B V R$, respectively, guard what is known as the principle of regional demarcation ("Regionalprinzip", Reifner and Evers 1998 and Maselli 2000).This principle is de facto enforced among both cooperative and savings banks. It stipulates that regional banks of these sectors must not conduct operations beyond the borders of their assigned region. The objective of this regulation is to ensure that rural and economically weak areas are also supplied with financial services in Germany.

This could explain the large number of impaired acquirers merging with healthy banks. The number of potential merger partners among savings and cooperatives may be limited to those that are geographically close. Table 5 depicts the number of mergers where both target and acquirer originate from the same region.

Table 5: Regional origin of merging banks

\begin{tabular}{crrrrrr} 
Region & \multicolumn{2}{c}{ County } & \multicolumn{2}{c}{ Municipality } & \multicolumn{2}{c}{ Total } \\
\hline Year & Savings & Coop's & Savings & Coop's & Savings & Coop's \\
\hline $\mathbf{1 9 9 4}$ & 28 & 60 & 3 & 29 & 47 & 108 \\
$\mathbf{1 9 9 5}$ & 15 & 34 & 7 & 19 & 29 & 67 \\
$\mathbf{1 9 9 6}$ & 6 & 35 & 4 & 30 & 17 & 78 \\
$\mathbf{1 9 9 7}$ & 4 & 44 & 2 & 25 & 8 & 84 \\
$\mathbf{1 9 9 8}$ & 1 & 91 & 1 & 41 & 4 & 159 \\
$\mathbf{1 9 9 9}$ & 5 & 129 & 1 & 36 & 15 & 209 \\
$\mathbf{2 0 0 0}$ & 6 & 136 & 4 & 50 & 15 & 238 \\
$\mathbf{2 0 0 1}$ & 13 & 88 & 3 & 36 & 24 & 169 \\
$\mathbf{2 0 0 2}$ & 8 & 77 & 1 & 22 & 17 & 129 \\
\hline Total & 86 & 694 & 26 & 288 & 176 & 1,241 \\
\hline
\end{tabular}

In 64 percent of the events, mergers among savings banks involve targets and acquirers that originated from the same county ("Kreis"). ${ }^{25}$ Approximately 15 percent of all mergers in this group concern banks from the same municipality

\footnotetext{
${ }^{24}$ Note that it remains unobservable who exactly ignites the merger itself, e.g. suggestions of the $D S G V$ or $B V R$, the local bank or even a recommendation of the Bundesbank and BaFin during extraordinary supervision talks.

${ }^{25}$ Equal to the sum of county and municipality mergers over total, i.e. $(86+26) / 176$, as one county is distinguished into multiple municipalities.
} 
( "Gemeinde $") .{ }^{26}$ For cooperative banks regional proximity of merger partners is even more evident. In almost 80 percent of all the cases, both parties are from the same county. A quarter of all cooperative bank mergers involve banks from the same municipality. ${ }^{27}$

There are two main reasons why mergers in the same region can be superior. First, it is possible that these transactions serve the purpose of reaching some required minimum size to operate efficiently. If two banks serve the same community with considerable overlap in their customer base, joined operations can help reduce unit costs if excess capacities, e.g. branches or employees, are reduced. Second, mergers among banks from the same vicinity may be superior because the acquirer is presumably familiar with local market conditions, e.g. weaknesses and strengths of local corporate firms, local politics or customer habits.

On the other hand, it is possible that the Regionalprinzip implies a lack of potential partners in a given region. Then it is more likely that target and acquirer may fail to complement each other, e.g. in terms of product range or funding structure. Mergers of banks located fairly close to each other might merely reflect restrictions imposed by the Regionalprinzip. Another reason why close regional proximity can result in inferior post merger performance is a lack of regional (income) diversification. The merged institute's revenue basis will be further concentrated within confined boundaries, thus exposing the bank to a larger degree to local macroeconomic conditions.

In this paper, we abstain from a full-fledged analysis of the costs and benefits of regional demarcation. However, we investigate whether mergers between nearby banks are more often a success or not. This is of interest to the public, regulators and bankers from respective head organisations in order to foster consolidation that is beneficial to all parties involved.

\subsection{Serial and Multiple Acquisitions}

Conventional wisdom of bank managers and consultants says that firms conducting more than one acquisition benefit from learning effects. Execution of a merger and the resulting post-merger integration process are subject to experience. If a firm acquires some merger expertise, subsequent transactions may yield better results in terms of both the level of improvements and time until realisation. ${ }^{28}$

The German bank merger wave is characterised by numerous serial acquirers, i.e. banks that absorbed more than one target during the observation period. Moreover, some banks absorbed more than one bank during a deal. We refer to the latter as multiple acquirers. In total, 903 banks acquired at least once one or more institute(s). Approximately a quarter $(330 / 1,241)$ of all mergers are

\footnotetext{
${ }^{26}$ Ideally, we investigate the geographical distance between target(s) and acquirer given the prevailing regional demarcation issued by the head organisations. Alas, this information is not available and we have to resort to publicly available regional indicators of counties and municipalities where banks are located.

${ }^{27}$ The number of counties in Germany is 438 and the number of municipalities is 2,333. For the few banks that were affected by changing borders in the course of time we assigned for all years the regional identifier of this most recent regional categorisation.

${ }^{28}$ For example, Lang and Welzel (1999) refer to statements of head organisations' officials that mergers require at least three years to materialise.
} 
conducted by serial acquirers. In 141 transactions, more than one target was absorbed by the same acquirer at the same time.

Clearly, potential learning effects from serial acquisitions can be offset by a complex post-merger integration of multiple targets. It simply may be beneficial if a bank already went through the integration process once or twice. But having to transfer, say, six different IT systems into a single new one can pose an excessive burden even to the most experienced merger manager.

Therefore, it is important in our view to investigate if learning effects prevailed or whether they have been counterbalanced due to a prohibitively high postmerger integration burden. To this end, we categorise acquirers according to four groups, identified by a clockwise arrangement in table 6 .

Table 6: Mean number of deals and targets between 1994-2002

Deal No Number of targets per deal

\begin{tabular}{crrrrrrr}
\hline & 1 & 2 & 3 & 4 & 5 & 6 & Total \\
\hline $\mathbf{1}$ & 804 & 85 & 6 & 7 & 0 & 1 & 903 \\
$\mathbf{2}$ & 240 & 27 & 3 & 1 & 0 & 0 & 271 \\
$\mathbf{3}$ & 42 & 8 & 0 & 0 & 1 & 1 & 52 \\
$\mathbf{4}$ & 11 & 1 & 0 & 0 & 0 & 0 & 12 \\
$\mathbf{5}$ & 3 & 0 & 0 & 0 & 0 & 0 & 3 \\
\hline Total & 1,100 & 121 & 9 & 8 & 1 & 2 & 1,241 \\
\hline \multicolumn{2}{l}{ Serial: more than one deal; Multiple: }
\end{tabular}

The first group in table 6 includes banks that acquired exactly one target during their first merger in the observation period. This category is the largest, including 804 mergers. We refer to it as "Single", depicted in the north-westerly cell in table 6 . On the one hand, these mergers do not suffer from multiple targets being integrated at the same time. On the other hand, these transactions are respectively the first deal the acquirer conducted during the observation period. Hence, no experience from prior transactions exists.

The second group includes those acquirers that absorbed more than one bank in their first transaction. This category is referred to as "Multiple". It contains 99 banks, depicted in row one and columns two to six. As can be seen in table 6, most multiple acquirers absorbed only two targets at the time, namely 85. But some banks acquired up to six banks at the time during their first transaction. This group therefore contains likely candidates where the complexity of post-merger integration is too high to yield beneficial results in terms of CE in the short run.

The total of banks in groups one and two is therefore the total of all acquirers (903), those that either acquired one or more institutes during their first acquisition. In subsequent rows, we further distinguish two additional groups: those that acquired one versus those that absorbed more banks after having merged beforehand.

The former category constitutes group three and includes mergers depicted in the south-east of table 6 . Banks in this group acquired more than one target after having acquired one or more banks previously. This category is referred to as "Both" and includes 42 banks. These mergers might be particularly prone to integration problems if, for example, a subsequent multiple acquisition is conducted while the preceding target is not yet fully integrated. 
Fourth and last, we include those banks that strictly limited themselves to absorbing just one target at the time but which did so several times during 1994 and 2002. This group is called "Serial" and represents the second but largest group with 306 banks.

We analyse below if mergers from any of the four groups Single, Multiple, Both or Serial yield systematically more often successful mergers. This allows us to investigate if excessive merging outweighs learning benefits.

All of the above raised questions clearly require us to define a successful merger. As noted previously, we define successful mergers in terms of $\mathrm{CE}$ in this paper. Within this strand of the literature, the attention rests traditionally either on a comparison of efficiency development after a merger or on relating the efficiency of merging and non-merging firms. We suggest in the next subsection a methodology to identify successful mergers along both dimensions simultaneously.

\section{Methodology}

Our first objective is to measure cost efficiency in a consolidating bank landscape taking mergers explicitly into account. As noted by Lang and Welzel (1999), this requires in a panel setting to model merged banks as new entities. This allows banks after a transaction to follow a new efficiency path over time. Therefore, we outline first our efficiency model.

Next, we suggest a taxonomy to define successful mergers that takes into account both efficiency development and the efficiency of non-merging banks.

\subsection{Cost Efficiency}

We estimate CE with stochastic frontier analysis and employ a cost model in conjunction with the intermediation approach (Sealey and Lindley 1977). ${ }^{29}$ A bank produces three outputs. These are interbank and commercial loans, $y_{1}$ and $y_{2}$, respectively, and securities, $y_{3}$. To this end banks utilise three inputs, which are demanded subject to prevailing prices, $w_{i}$, and the technology constraint, depicted by a transformation function $T(y, x, z)$. A bank employs fixed assets, $x_{1}$, labour, $x_{2}$, and borrowed funds, $x_{3}$. In addition, we include equity capital, $z$, to account for alternative funding sources and heterogeneous risk-preferences among banks. Our sample includes all savings and cooperative banks operating in Germany between 1993 and 2003.

To estimate an optimal cost frontier for this unbalanced panel, we follow Greene (2002) and use a bank-specific fixed effects stochastic frontier model with time-variant inefficiency. Thereby, systematic bank-specific heterogeneity due to differences in size, sector and regional location of banks are now captured by the bank-specific fixed effects. To account explicitly for ongoing consolidation, we follow the approach suggested by Lang and Welzel (1999). A merging bank is treated as a new bank. We allow a merged bank to follow a different optimal cost

\footnotetext{
${ }^{29} \mathrm{We}$ focus on $\mathrm{CE}$ as cost pressure is more frequently cited as one of the major reasons in German banking to merge. A natural extension is to examine profit efficiency. Given the limited scope of this chapter this approach is postponed for further research.
} 
path inasmuch as each bank involved in a merger is treated with a separate fixed effect $\alpha_{k}$.

This approach is markedly different from, say, including a dummy variable for mergers in the cost frontier specification. ${ }^{30}$ Such a model boils down to estimating one identical intercept for all banks that merge, which might be different from the cost functions intercept of non-merging banks. However, it is a strong assumption that the cost intercept is identical for all merging banks.

We include a time trend and interaction terms to account for technological change. The reduced form of optimal cost is specified using the translog functional form and takes the following form: ${ }^{31}$

$$
\begin{aligned}
\ln C_{k t}= & \alpha_{k}+\sum_{i=1}^{3} \alpha_{i} \ln w_{i k t}+\sum_{m=1}^{3} \beta_{m} \ln y_{m k t}+\delta_{0} \ln z_{k t} \\
& +\frac{1}{2} \sum_{i=1}^{3} \sum_{j=1}^{3} \alpha_{i j} \ln w_{i k t} \ln w_{j k t}+\sum_{i=1}^{3} \sum_{m=1}^{3} \gamma_{i m} \ln w_{i k t} \ln y_{m k t} \\
& +\frac{1}{2} \sum_{m=1}^{3} \sum_{n=1}^{3} \beta_{m n} \ln y_{m k t} \ln y_{n k t}+\frac{1}{2} \delta_{1}\left(\ln z_{k t}\right)^{2} \\
& +\sum_{i=1}^{3} \omega_{i} \ln w_{i k t} \ln z_{k t}+\sum_{m=1}^{3} \zeta_{m} \ln y_{m k} \ln z_{k t}+\eta_{0} t+\frac{1}{2} \eta_{1}(t)^{2} \\
& +\sum_{i=1}^{3} \kappa_{i} \ln w_{i k t} t+\sum_{m=1}^{3} \tau_{m} \ln y_{m k t} t+\varepsilon_{k t} .
\end{aligned}
$$

In any year $t$, a bank $k$ can deviate from optimal cost due to random noise, $v_{k t}$, or inefficient use of in- and outputs, $u_{k t}$. To distinguish these two effects, we specify a composed total error, $\varepsilon_{k t}$. For a cost frontier inefficiency leads to above frontier costs. Therefore, the total error is $\varepsilon_{k t}=u_{k t}+v_{k t}$. The random error term $v_{k t}$ is assumed i.i.d. with $v_{k t} \sim N\left(0, \sigma_{v}^{2}\right)$ and independent of the explanatory variables. The inefficiency term is i.i.d. with $u_{k t} \sim N\left|\left(0, \sigma_{u}^{2}\right)\right|$ and independent of the $v_{k t}$. It is drawn from a non-negative distribution truncated at zero. Greene (2002) further notes that the $\alpha_{k}$ 's are allowed to be correlated with the cost function variables, $y_{k t}, w_{k t}$ and $z_{k t}$. Any systematic deviations from the frontier due to heterogeneity across banks are captured by the fixed effect.

Note that inefficiency can vary over time but, apart from the distributional assumption, is not further specified to follow any particular trend over time. This approach has the virtue that efficiency can, for example, deteriorate in the immediate aftermath of a merger but is able to "recover" after some time has elapsed. At the same time, the cost frontier and, thus, the associated inefficiency and its development is bank-specific, as it depends to some degree on the fixed effect.

To allow banks to enter a new efficiency path, we assign a new identifier to each bank after a merger. To illustrate this approach consider figure 1.

\footnotetext{
${ }^{30}$ The latter alternative would resemble the kernel model used in Bos et al. (2004) where a dummy for merging bans is specified in addition to the heterogeneity variables, $h_{k}$, on region, banking group and size.

${ }^{31}$ We impose homogeneity and symmetry restrictions as in Lang and Welzel (1999).
} 
Figure 1: Treatment of merging banks

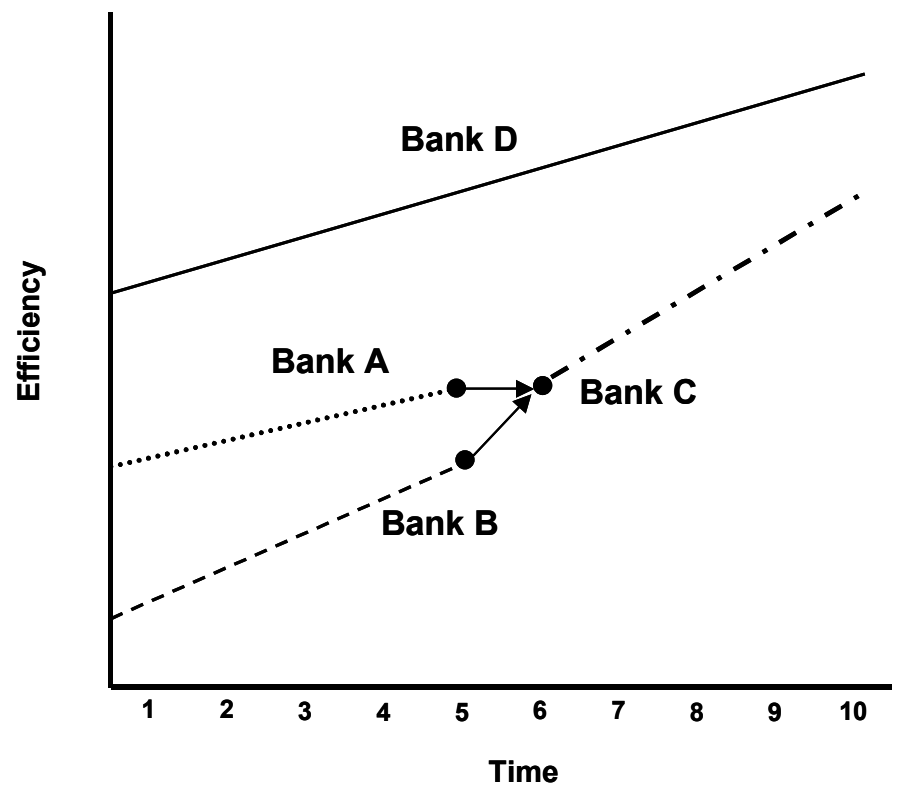

We assume for the sake of expositional ease that all banks A through D exhibit a positive, linear trend of efficiency over time. ${ }^{32}$ Subject to its fixed effect, $\alpha_{D}$, bank $\mathrm{D}$ illustrates a bank that is not merging during the observation period and exhibits continuously improving CE. Assume now that compared to the non-merging bank $\mathrm{D}$ two relatively less efficient banks $\mathrm{A}$ and $\mathrm{B}$ merge. Let the relatively more efficient bank A acquire the relatively less efficient, but faster improving, bank B in period 5. Then, efficiency differentials discussed in section 3.1 can be measured as the $\mathrm{CE}$ differential one year prior to merging. To adequately evaluate the CE effects of merging, Lang and Welzel (1999) stress the importance to treat the merged banks as if it is a new entrant to the market. Following their suggestion we therefore assign a new identifier to this merged institute, C. Estimated optimal cost, and hence efficiency, for this "new" bank are then subject to a new separate fixed effect. Put differently, the location of the optimal frontier for this new emerged bank $\mathrm{C}$ is different from that of bank $\mathrm{A}$ and bank $\mathrm{B}$. Thereby, we allow efficiency to develop over time on a different path compared to that of the two banks prior to the merger.

We are interested not only in a comparison to non-merging banks but especially to distinguish successful and unsuccessful mergers. Let us therefore turn to our definition of successful mergers on the basis of cost efficiency.

\subsection{Successful Mergers}

Identification of successful mergers on the basis of the level of efficiency alone might be misleading. Consider as an example a bank that merged in 1995. Assume it exhibits $\mathrm{CE}$ of 80 percent in 1997 relative to an average CE of non-merging

\footnotetext{
${ }^{32}$ Note, that such a development is by no means pre-determined by our specification of the frontier.
} 
banks of 75 percent. On this basis alone the merger may then be considered a success. But if the bank exhibited cost efficiency of 85 percent in the year of the merger, 1995, the decline by 5 percent is hardly an achievement.

We therefore compare mergers along two dimensions. The first dimension is the acquirer's change in $\mathrm{CE}$ in year $t$ relative to the year of the merger. The second is the level of $\mathrm{CE}$ of the merged institute in year $t$ after the merger.

The first dimension captures changes in CE. As many practitioners point out, potential gains require some time until they materialise. Therefore, we report efficiency changes for a range of time $t$ from 1 until $9 .^{33}$ To evaluate whether a particular merger was successful, we use as a benchmark the average efficiency change of those banks that never merged, i.e. mean $\mathrm{CE}$ of all banks like $\mathrm{D}$ in figure 1 in year $t{ }^{34}$ Hence, a decline in efficiency need not necessarily imply a bad merger. If a bank suffered, for example, from a five percent drop in efficiency but the group of non-merging banks experienced a drop of ten percent, the merger helped to offset the negative trend. For example, we compare the two-year efficiency change of a bank that merged in 1995 in 1997 with the efficiency change of non-merging banks in the same two years.

The second dimension is the level of CE of merging and non-merging banks. For example, along this second dimension, we compare a bank that merged in 1995 two years after the merger relative to the level of mean $\mathrm{CE}$ of non-merging banks in 1997. Consider as an example figure 2.

We define mergers in the north-eastern quadrant, group I, as a success. These transactions yield, first, higher efficiency levels compared to non-merging banks in the year examined and, second, enjoyed an increase in efficiency since the merger above the mean $\mathrm{CE}$ change of non-merging banks during the same time period. Below, we examine if these successful mergers also exhibit other favourable KPI, e.g. higher profitability and lower CI ratios. Likewise, we examine whether successful (as well as unsuccessful) mergers exhibit a clear profile in terms of deal-specific characteristics in terms of transferring skills, regional proximity of partners, distress and learning effects.

The south-eastern quadrant, group II, is deemed unsuccessful. Merged banks exhibit above non-merging average $\mathrm{CE}$ two years after the transaction. But the change in $\mathrm{CE}$ is lower compared to the mean change of non-merging banks. Such mergers are unsuccessful because, for the example of an increasing industry trend in CE, the bank failed to match positive market developments. This could be the case if the acquiring bank was already highly cost efficient prior to the merger leading to high levels of $\mathrm{CE}$ in the merger year itself. ${ }^{35} \mathrm{~A}$ high level of CE could have led to a too relaxed attitude towards rolling out superior cost management skills at the target quickly. We expect to obtain an indication if banks with ex-

\footnotetext{
${ }^{33}$ We have information about merger acivities between 1994 and 2002. In addition, we have balance sheet and profit and loss account data for the period 1993 until 2003. Hence, the maximum number of post-merger years available is nine years, namely from 1995 to 2003.

${ }^{34}$ We refer henceforth to those banks that never merged as non-merging banks. Thereby, we avoid to compare in a given year merging bank's performance to a benchmark that includes some banks which may merge later on. In fact, a banks' CE one year prior to merger may already differ markedly from $\mathrm{CE}$ of banks never merging and can thus constitute a poor benchmark sample.

${ }^{35}$ Note, however, that we do not consider here how efficient the bank was in the year of the merger but compare it to the benchmark $t$ years after the merger.
} 
Figure 2: Performance of 1995 mergers two years after transaction

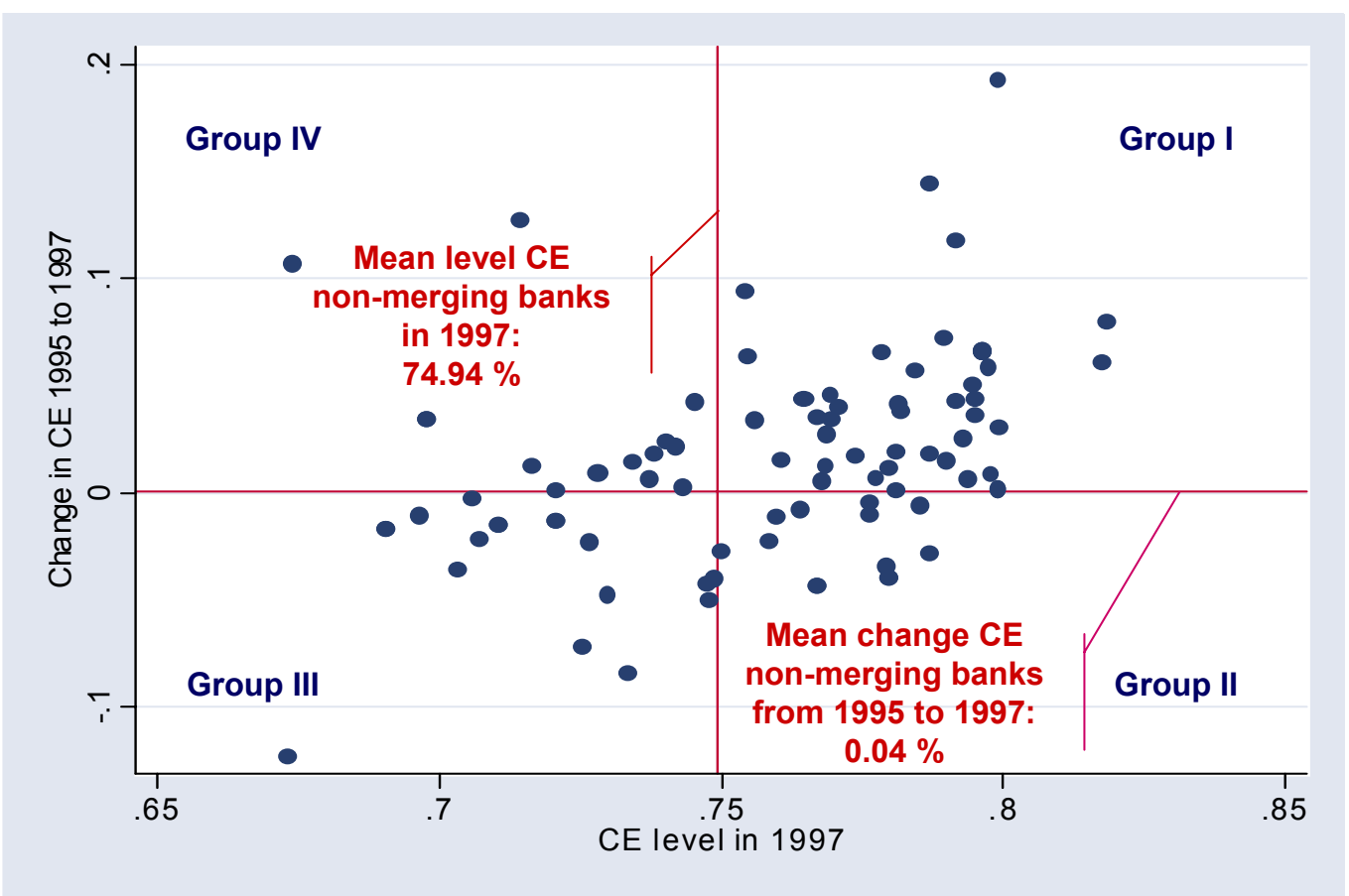

treme pre-merger differentials fall relatively more often into this (or other) merger groups, reflecting either inability or sheer neglect of transferring knowledge.

The south-western quadrant, group III, depicts the worst mergers. In the above example, mergers conducted in 1995 resulted two years later in CE levels below those of non-merging banks in 1997, i.e. 74.94 percent. Moreover, these banks exhibit a change in CE below the average of non-merging banks, namely 0.04 percent. We expect to see that these banks do also perform poorly in terms of traditional KPI as they exhibit in terms of CE neither high levels of cost management skill nor above average improvements.

Finally, the north-western quadrant, group IV, depicts banks with below nonmerging banks' mean $\mathrm{CE}$ but with above average changes in $\mathrm{CE}$. Consequently, these transactions are not univocally a success. But they may have the largest potential as promising changes in CE may indicate above average efficiency after some more time. We are interested below if, for example, especially those mergers are a success where one partner suffered from clear deficiencies as reflected by distress. While turning around a distressed bank could imply below average levels of $\mathrm{CE}$ for a while, focused restructuring efforts could show up in our taxonomy as above average improvements of CE.

Before turning to an assessment of the German merger wave on the basis of our results let us briefly point out a potential caveat. ${ }^{36}$ The two dimensions on which our grouping is based, namely the level and change of CE, respectively, are not entirely independent from each other. A bank that exhibits above average CE

\footnotetext{
${ }^{36}$ We conserve on space and do not provide parameter estimates and general descriptive statistics on efficiency. They are available upon request from the author.
} 
changes after up to nine years after the merger is also more likely to end up with a level of CE above the average CE of non-merging banks. However, we argue that most alternative approaches that rely either on levels of $\mathrm{CE}$ or, for that matter, other KPI do suffer from even more severe problems as these approaches neglect the development of the chosen performance ratio entirely.

\section{Results}

We present first the efficiency effects of merging banks according to the taxonomy described in section 4.2. Compared to the group of non-merging banks we define as a success those transactions that yield both (i) higher levels of cost efficiency after the merger and (ii) exhibit above average changes in efficiency. Based on this categorisation we subsequently investigate the issues raised.

\subsection{Identification of Successful Mergers}

In table 7 we depict for each cohort of merger years the difference between mean $\mathrm{CE}$ of merging versus non-merging banks. We do so for both the level of and the change in $\mathrm{CE}{ }^{37}$

Table 7: Cost efficiency differentials between merging and non-merging banks

\begin{tabular}{|c|c|c|c|c|c|c|c|c|c|c|}
\hline \multirow[b]{2}{*}{ Merger } & \multirow[b]{2}{*}{ Differential $^{1)}$} & \multicolumn{9}{|c|}{ Years elapsed } \\
\hline & & 1 & 2 & 3 & 4 & 5 & 6 & 7 & 8 & 9 \\
\hline \multirow[t]{2}{*}{1994} & CE Level & $1.4^{* * *}$ & 0.3 & $0.7^{*}$ & $1.2^{* * *}$ & 0.5 & $1.6^{* * *}$ & $1.2^{* *}$ & $1.6^{* *}$ & 0.9 \\
\hline & CE Change & $2.1^{* * *}$ & $1.1^{* *}$ & $1.0^{* *}$ & $1.7^{* * *}$ & $1.0^{* * *}$ & $2.2^{* * *}$ & $2.0^{* *}$ & $2.4^{* * *}$ & 1.4 \\
\hline \multirow[t]{2}{*}{1995} & CE Level & 0.1 & 0.7 & 0.3 & 0.5 & $1.6^{* *}$ & 1.0 & 0.9 & 0.9 & \\
\hline & CE Change & $0.9^{* *}$ & $1.6^{* * *}$ & $1.3^{* *}$ & $1.7^{* *}$ & $2.7^{* * *}$ & $1.9^{* *}$ & $2.0^{*}$ & $2.5^{* *}$ & \\
\hline \multirow[t]{2}{*}{1996} & CE Level & 0.7 & $1.3^{* * *}$ & $1.4^{* * *}$ & 0.5 & 0.8 & 0.3 & 0.8 & & \\
\hline & CE Change & -0.4 & 0.2 & 0.5 & -0.5 & -0.1 & -1.0 & -0.6 & & \\
\hline \multirow[t]{2}{*}{1997} & CE Level & $1.5^{* * *}$ & $1.3^{* *}$ & 0.7 & 0.4 & 1.3 & 0.6 & & & \\
\hline & CE Change & $0.9^{* *}$ & 0.7 & 0.2 & -0.1 & 0.9 & 0.3 & & & \\
\hline \multirow[t]{2}{*}{1998} & CE Level & $0.9^{* *}$ & 0.1 & 0.5 & $1.9^{* * *}$ & $2.0^{* * *}$ & & & & \\
\hline & CE Change & -0.2 & $-1.0^{*}$ & -0.4 & $1.2^{*}$ & 1.2 & & & & \\
\hline \multirow[t]{2}{*}{1999} & CE Level & 0.4 & $1.3^{* * *}$ & $1.3^{* * *}$ & $0.9^{*}$ & & & & & \\
\hline & CE Change & $-0.9^{* *}$ & 0.2 & 0.3 & 0.0 & & & & & \\
\hline \multirow[t]{2}{*}{2000} & CE Level & $1.6^{* * *}$ & $1.2^{* * *}$ & $1.3^{* * *}$ & & & & & & \\
\hline & CE Change & 0.6 & 0.3 & 0.4 & & & & & & \\
\hline \multirow[t]{2}{*}{2001} & CE Level & $1.0^{* *}$ & $2.1^{* * *}$ & & & & & & & \\
\hline & CE Change & $0.9^{* * *}$ & $2.0^{* * *}$ & & & & & & & \\
\hline \multirow[t]{2}{*}{2002} & CE Level & $1.9^{* * *}$ & & & & & & & & \\
\hline & CE Change & $0.8^{* *}$ & & & & & & & & \\
\hline \multirow[t]{2}{*}{ Total } & CE Level & 1.1 & 1.1 & 1.0 & 1.0 & 1.2 & 1.0 & 1.0 & 1.3 & 0.9 \\
\hline & CE Change & 0.6 & 0.7 & 0.7 & 0.5 & 1.1 & 1.2 & 2.1 & 2.3 & 1.2 \\
\hline
\end{tabular}

1) Differentials calculated as merger less non-merging bank efficiency in percentages.

Note: ${ }^{* * *, * * *}$ depict significant differences at the 1,5 and 10 percent level, respectively.

\footnotetext{
${ }^{37}$ Recall, that the level of $\mathrm{CE}$ is compared in any given post-merger year with the according group of non-merging banks of that year and that the change of CE employs the respective merger year as base year.
} 
On average, the post-transaction level of merging banks' $\mathrm{CE}$ is higher compared to non-merging banks. In addition, the change in efficiency compared to the respective year of the merger is also above the mean efficiency change among nonmerging banks. Except for those mergers occurring in 1996 and 1997, most level and change differentials are positive and significantly different from zero. Thus, mergers have on average been a success in Germany's cooperative and savings bank sectors.

However, this success is on average modest regarding the level of improvements, namely around a mere percentage point. The change of $\mathrm{CE}$ is more favourable after considerable time has elapsed, say between seven and eight years after the merger. Then, efficiency changes compared to the year of merger are slightly larger compared to quick wins just one or two years after the merger. But even a two percent increase can hardly be called a splendid performance. Interestingly, for those mergers that were executed around the time of booming equity markets in Germany, 1998 and 1999, the change of CE has been below the average of non-merging banks up to three years after the transaction. This could indicate that managers did not focus on keeping production cost efficient. In times when the temptations to realise quick gains in new business arenas may have been paramount from a banker's point of view, careful cost management was apparently of secondary interest.

Table 7 depicts mean efficiency differentials. To further assess how many mergers were a success we turn our attention to the distribution of mergers according to the four quadrant taxonomy described in section 4.2 .

Table 8: Number of banks per quadrant x years after merger

\begin{tabular}{|c|c|c|c|c|c|}
\hline & \multicolumn{4}{|c|}{ Group } & Total \\
\hline Years & I & II & III & IV & $\mathbf{N}$ \\
\hline elapsed & Success & Change loser & Total loser & Level loser & \\
\hline 1 & 544 & 317 & 175 & 91 & 1,127 \\
\hline 2 & 479 & 183 & 191 & 50 & 903 \\
\hline 3 & 323 & 145 & 166 & 43 & 677 \\
\hline 4 & 236 & 86 & 117 & 27 & 466 \\
\hline 5 & 153 & 57 & 72 & 24 & 306 \\
\hline 6 & 106 & 34 & 51 & 9 & 200 \\
\hline 7 & 72 & 19 & 48 & 4 & 143 \\
\hline 8 & 56 & 11 & 26 & 6 & 99 \\
\hline 9 & 27 & 10 & 17 & 5 & 59 \\
\hline
\end{tabular}

The number of banks in group I is throughout the years after merging at around 50 percent. Thus, we conclude that in terms of CE every second savings and cooperative bank merger resulted in a successful merger. To avoid that multiple acquirers, i.e. those that absorbed more than one bank in a given year, are assigned too much weight in the categorisation of mergers, we included these banks' post-merger performance only once in each year they conduct multiple acquisitions. ${ }^{38}$

\footnotetext{
${ }^{38} \mathrm{We}$ did the same for the calculation of efficiency differentials in table 7 .
} 
Another indication provided by table 8 refers to the declining share of group II mergers and the increasing share of group III mergers over time. A possible explanation is that banks suffering from below non-merging banks' CE changes ultimately also fall below the mean level of non-merging banks' CE ratios. Then, these banks transit into the total loser group if they continuously experience below average CE changes. However, the observation of switching shares of group II and III, respectively, can only be regarded as an indication for the aforementioned interpretation. This is because in table 8 it is also possible that the share of a group stays fairly constant, such as for group IV, but the composition of individual institutes continuously changes from year to year. To draw stronger inference we would therefore have to construct transition matrices and seek to estimate the probability of transition given a whole range of bank-specific and environmental variables. ${ }^{39}$

While we argue that efficiency is particularly suited to evaluate the success of mergers in the course of time, we acknowledge the inherent interest of practitioners and regulators in alternative KPI to assess the (lack of) virtues of bank mergers. We therefore turn to the development of KPI introduced in table 3 for each of our four merger groups.

\subsection{Characteristics of Mergers across Groups}

In table 9 we show the KPI ratios introduced in section 2.3 in addition to mean CE over time and banking groups. ${ }^{40}$ Overall, KPI after a merger bear markedly different information between savings and cooperative banks. In addition, differences between traditional KPI across groups are not significant in the long run. Thus, they are by and large uninformative when categorising mergers on the basis of CE six years after the merger. ${ }^{41}$ This indicates that after approximately six years other factors than a merger determine these indicators. We therefore concentrate in table 9 on the medium and short run.

Consider savings banks first. We find that profitability is highest for mergers exhibiting above benchmark $\mathrm{CE}$ levels but below benchmark $\mathrm{CE}$ changes, i.e. group IV mergers. ${ }^{42}$ At the same time both net interest margins and concentration are highest for group IV mergers. Consequently, high profitability may be due to market power. We consider such a merger not a success and conclude that market power concerns are appropriate for savings banks that exhibit above benchmark

\footnotetext{
${ }^{39} \mathrm{In}$ fact, it is an interesting question in its own right which banks transit over time from one group to another for what reason. An example of an explicit account of the transition dynamics associated with bank consolidation can be found in Robertson (2001). Unfortunately, such an approach is beyond the scope of this chapter and subject to future research.

${ }^{40}$ Note, that we do not compare each KPI to a benchmark of non-merging banks. While in principle any performance indicator could be used we focus here on CE because of its ability to assess performance to produce economically efficient. Here, we limit ourselves to investigate how KPI of those mergers developed that we identified on the basis of our CE taxonomy as support-worthy or not.

${ }^{41}$ This holds especially for savings banks but also for cooperative banks, albeit to a lesser degree.

${ }^{42}$ As noted earlier it would be a worthwhile extension to conduct merger evaluation also on the basis of profit efficiency (PE). We know from previous chapters that PE is higher correlated with ROE compared to CE. Thus, one might suspect that according to such an alternative categorisation ROE are univocally the highest for successful (PE) mergers.
} 
Table 9: Mean performance and structure indicators across mergers

\begin{tabular}{|c|c|c|c|c|c|c|c|c|c|c|c|}
\hline \multirow{2}{*}{$\frac{\text { Years }}{\text { One }}$} & \multirow{2}{*}{$\frac{\text { KPI }}{\text { Group }}$} & \multicolumn{5}{|c|}{ Savings } & \multicolumn{5}{|c|}{ Cooperatives } \\
\hline & & $I$ & $I I$ & $I I I$ & $I V$ & $p$-value $e^{5)}$ & $I$ & $I I$ & $I I I$ & $I V$ & $p$-value ${ }^{5)}$ \\
\hline & $\mathrm{CE}$ & 78.17 & 76.85 & 71.78 & 71.99 & 0.000 & 78.04 & 76.74 & 71.47 & 72.65 & 0.000 \\
\hline & $\mathrm{ROE}$ & 12.18 & 9.92 & 11.15 & 12.43 & 0.633 & 10.09 & 9.11 & 5.44 & 10.89 & 0.000 \\
\hline & CI & 70.05 & 70.09 & 70.95 & 76.30 & 0.066 & 73.45 & 74.83 & 80.91 & 74.95 & 0.000 \\
\hline & NIM & 2.72 & 2.60 & 2.74 & 3.04 & 0.003 & 2.82 & 2.81 & 2.90 & 2.86 & 0.009 \\
\hline & $\operatorname{Prod}^{1)}$ & 0.284 & 0.293 & 0.301 & 0.370 & 0.000 & 0.311 & 0.329 & 0.428 & 0.357 & 0.000 \\
\hline & $\mathrm{UC}^{2)}$ & 5.57 & 5.50 & 5.80 & 5.84 & 0.008 & 5.78 & 5.98 & 6.19 & 6.02 & 0.000 \\
\hline & $\mathrm{INC}^{3)}$ & 7.90 & 8.07 & 7.71 & 8.53 & 0.091 & 10.80 & 10.88 & 10.92 & 10.47 & 0.468 \\
\hline & $\mathrm{HHI}^{4)}$ & 5183 & 5494 & 5064 & 6771 & 0.065 & 3735 & 3556 & 3915 & 4063 & 0.175 \\
\hline \multicolumn{12}{|l|}{ Three } \\
\hline & $\mathrm{CE}$ & 78.08 & 76.69 & 73.00 & 72.89 & 0.000 & 78.41 & 76.64 & 72.14 & 73.67 & 0.000 \\
\hline & ROE & 18.29 & 10.07 & 10.73 & 18.65 & 0.006 & 10.15 & 7.89 & 8.71 & 10.05 & 0.006 \\
\hline & CI & 66.06 & 69.80 & 71.55 & 68.86 & 0.042 & 72.89 & 75.00 & 78.20 & 76.90 & 0.000 \\
\hline & NIM & 2.77 & 2.53 & 2.63 & 2.93 & 0.012 & 2.79 & 2.80 & 2.82 & 2.77 & 0.610 \\
\hline & $\operatorname{Prod}^{1)}$ & 0.295 & 0.283 & 0.303 & 0.342 & 0.010 & 0.300 & 0.322 & 0.328 & 0.323 & 0.000 \\
\hline & $\mathrm{UC}^{2)}$ & 5.31 & 5.41 & 5.41 & 5.18 & 0.562 & 5.61 & 5.76 & 5.87 & 5.80 & 0.000 \\
\hline & $\mathrm{INC}^{3)}$ & 8.33 & 8.70 & 8.97 & 9.96 & 0.001 & 11.45 & 11.25 & 11.65 & 10.26 & 0.270 \\
\hline & $\mathrm{HHI}^{4)}$ & 5850 & 5304 & 6350 & 7334 & 0.182 & 3835 & 3661 & 3755 & 3942 & 0.887 \\
\hline \multicolumn{12}{|l|}{ Six } \\
\hline & $\mathrm{CE}$ & 78.63 & 76.24 & 71.17 & 73.72 & 0.000 & 77.84 & 76.12 & 71.60 & 73.74 & 0.000 \\
\hline & $\mathrm{ROE}$ & 13.01 & 12.24 & 9.16 & 16.73 & 0.161 & 8.24 & 7.66 & 6.91 & 4.81 & 0.180 \\
\hline & CI & 68.01 & 69.79 & 67.89 & 65.90 & 0.932 & 73.98 & 77.65 & 81.77 & 83.98 & 0.005 \\
\hline & NIM & 2.56 & 2.35 & 2.56 & 2.74 & 0.336 & 2.75 & 2.69 & 2.73 & 2.64 & 0.756 \\
\hline & $\operatorname{Prod}^{1)}$ & 0.293 & 0.277 & 0.296 & 0.277 & 0.386 & 0.295 & 0.301 & 0.343 & 0.325 & 0.073 \\
\hline & $\mathrm{UC}^{2)}$ & 5.02 & 5.18 & 5.11 & 5.07 & 0.728 & 5.61 & 5.70 & 6.09 & 6.13 & 0.010 \\
\hline & $\mathrm{INC}^{3)}$ & 10.63 & 9.74 & 10.29 & 9.66 & 0.636 & 11.69 & 11.61 & 11.38 & 12.82 & 0.819 \\
\hline & $\mathrm{HHI}^{4)}$ & 7139 & 5422 & 7386 & 7542 & 0.696 & 3961 & 3652 & 3577 & 3587 & 0.912 \\
\hline
\end{tabular}

1) Productivity measured as FTE per mn Euro of total assets; ${ }^{2}$ ) Unit cost measured as Euro-cent

of total cost to Euro of total assets; ${ }^{3}$ ) Income structure measured as fee to total income;

4) HHI in points between 1 and 10,$\left.000 ;{ }^{5}\right)$ p-value for Kruskall-Wallis test of equal populations.

Note: All mean KPI in percentages unless noted otherwise.

CE changes. Our taxonomy of success on the basis of CE seems to avoid identification of such mergers as desirable. With respect to potential motives of merging we find little support that either scope or scale economies are realised in savings bank mergers. The share of fee to interest income and unit costs are not the most favourable ones for our success group I. However, our productivity proxy indicate that successful mergers are those with high labour productivity. Consequently, savings bank mergers in Germany might indeed be a vehicle to reduce the work force under comparably rigid labour laws. In a sense this result is akin to findings of Lang and Welzel (1999) who report that only those mergers yield above average efficiency growth which are accompanied by closure of branches.

Consider cooperative banks next. As for savings banks, we find that profitability is high for group I but also for group IV mergers. While the CI ratio is univocally the lowest for our identification of successful mergers, this result implies that $\mathrm{CE}$ and profitability measures contain different information. In contrast to savings banks, we find that neither margins nor concentration is particularly high for group IV mergers. In fact, both measures are hardly ever significantly different across merger groups. We conclude that market power concerns are of minor importance for cooperative bank mergers. With regard to potential merger reasons we find as for savings banks that productivity is most favourable for successful mergers. Thus, cooperatives may have used mergers as well to improve the productivity of their labour force. In addition, unit costs are the lowest for successful mergers. This mirrors the frequently raised objective of cooperative 
banks to increase the size of their operations to realise economies of scale. Note also that both ratios are the only significant ones in the long run. In contrast, income diversification is an unlikely candidate for a merger motive as differences across groups are insignificant in all periods.

The next subsections investigate if we can also identify some deal-characteristics that either facilitate or obstruct a merger to become a success or not. This discussion follows the four characteristics raised at the beginning of section 3 .

\subsection{Transfer of Skill}

The first deal-specific characteristic in section 3.1 inquires if especially those mergers are successful that involve partners with large ex ante CE differentials.

To this end we create nine equally sized groups of $\mathrm{CE}$ differentials in table 10. We depict the mean difference in $\mathrm{CE}$ levels between the acquirer and the target one year prior to the merger, $C E_{t-1}^{A}-C E_{t-1}^{T}$, one, three and six years after the merger occurred. ${ }^{43}$ We then compare the relative frequencies of each merger group I through IV for each of these nine CE differential groups to the population representation.

Table 10: Cost efficiency differentials between acquirers and targets

\begin{tabular}{|c|c|c|c|c|c|c|c|c|c|c|c|}
\hline \multirow[t]{2}{*}{ Years } & \multirow[b]{2}{*}{ Group } & \multicolumn{9}{|c|}{ Pre-merger CE differential groups } & \multirow[t]{2}{*}{ Total } \\
\hline & & 1 & 2 & 3 & 4 & 5 & 6 & 7 & 8 & 9 & \\
\hline \multirow{6}{*}{ One } & $C E_{t-1}^{A}-C E_{t-1}^{T}$ & $-7.8 \%$ & $-3.1 \%$ & $-1.3 \%$ & $-0.2 \%$ & $0.1 \%$ & $1.2 \%$ & $2.6 \%$ & $4.5 \%$ & $11.7 \%$ & $0.8 \%$ \\
\hline & $\mathrm{I}$ & $53 \%$ & $53 \%$ & $47 \%$ & $47 \%$ & $44 \%$ & $43 \%$ & $43 \%$ & $54 \%$ & $50 \%$ & $48 \%$ \\
\hline & II & $18 \%$ & $31 \%$ & $31 \%$ & $34 \%$ & $19 \%$ & $31 \%$ & $30 \%$ & $26 \%$ & $31 \%$ & $28 \%$ \\
\hline & III & $21 \%$ & $12 \%$ & $16 \%$ & $13 \%$ & $19 \%$ & $21 \%$ & $17 \%$ & $11 \%$ & $10 \%$ & $16 \%$ \\
\hline & IV & $7 \%$ & $4 \%$ & $6 \%$ & $6 \%$ & $18 \%$ & $5 \%$ & $10 \%$ & $8 \%$ & $10 \%$ & $8 \%$ \\
\hline & Total N & 126 & 126 & 126 & 126 & 126 & 126 & 126 & 126 & 126 & 1,127 \\
\hline \multirow{6}{*}{ Three } & $C E_{t-1}^{A}-C E_{t-1}^{T}$ & $-6.9 \%$ & $-2.5 \%$ & $-1.0 \%$ & $-0.1 \%$ & $0.0 \%$ & $0.8 \%$ & $2.3 \%$ & $4.0 \%$ & $10.6 \%$ & $0.8 \%$ \\
\hline & $\mathrm{I}$ & $53 \%$ & $47 \%$ & $51 \%$ & $48 \%$ & $54 \%$ & $60 \%$ & $52 \%$ & $51 \%$ & $39 \%$ & $48 \%$ \\
\hline & II & $22 \%$ & $19 \%$ & $21 \%$ & $19 \%$ & $13 \%$ & $5 \%$ & $29 \%$ & $16 \%$ & $24 \%$ & $21 \%$ \\
\hline & III & $18 \%$ & $25 \%$ & $23 \%$ & $28 \%$ & $21 \%$ & $28 \%$ & $13 \%$ & $25 \%$ & $25 \%$ & $25 \%$ \\
\hline & IV & $7 \%$ & $9 \%$ & $5 \%$ & $5 \%$ & $12 \%$ & $7 \%$ & $5 \%$ & $8 \%$ & $12 \%$ & $6 \%$ \\
\hline & Total N & 76 & 75 & 75 & 75 & 76 & 75 & 75 & 75 & 75 & 677 \\
\hline \multirow[t]{6}{*}{ Six } & $C E_{t-1}^{A}-C E_{t-1}^{T}$ & $-4.6 \%$ & $-0.9 \%$ & $0.0 \%$ & $0.0 \%$ & $0.0 \%$ & $0.1 \%$ & $1.3 \%$ & $3.4 \%$ & $10.1 \%$ & $1.0 \%$ \\
\hline & $\mathrm{I}$ & $52 \%$ & $45 \%$ & $64 \%$ & $55 \%$ & $70 \%$ & $59 \%$ & $55 \%$ & $59 \%$ & $41 \%$ & $53 \%$ \\
\hline & II & $17 \%$ & $23 \%$ & $9 \%$ & $27 \%$ & $0 \%$ & $14 \%$ & $18 \%$ & $9 \%$ & $14 \%$ & $17 \%$ \\
\hline & III & $30 \%$ & $27 \%$ & $27 \%$ & $9 \%$ & $22 \%$ & $27 \%$ & $27 \%$ & $27 \%$ & $41 \%$ & $26 \%$ \\
\hline & IV & $0 \%$ & $5 \%$ & $0 \%$ & $9 \%$ & $9 \%$ & $0 \%$ & $0 \%$ & $5 \%$ & $5 \%$ & $5 \%$ \\
\hline & Total N & 23 & 22 & 22 & 22 & 23 & 22 & 22 & 22 & 22 & 200 \\
\hline
\end{tabular}

Note: $C E_{t-1}^{A}-C E_{t-1}^{T}$ depicts mean CE of acquirer less CE of target one year prior to merger;

multiple acquirers included only once; each bank treated separately after merger.

We draw three major conclusions. First, on average mergers involved pairs where the acquirer is slightly more efficient prior to the merger, namely by about one percentage point of CE. Given the tiny difference we concede that only little room prevailed as to "import" superior managerial skills from either party into

\footnotetext{
${ }^{43}$ For multiple acquirers we calculated the differential between the acquirer's CE level relative to the average CE level of all targets weigthed by the respective target's total assets in the period prior to merger.
} 
the merged institute. Put differently, the desire to transfer skill or to replace less able incumbent managers appears to be of lesser importance for most mergers of cooperative and savings banks.

Second, large differentials of either kind, i.e. groups 1 and 9 in table 10, are in the short run more frequently successful compared to those mergers that involve banks with small $\mathrm{CE}$ differentials. Interestingly, those mergers where the target is the dominant partner are identified considerably more often a success compared to those where the acquirer dominates the target by a similarly large $\mathrm{CE}$ differential. This result suggests that it is not per se important as to which of the partners involved is dominant. We conclude that in the short run large differentials in general spur realisation of "quick wins" as both minimum and maximum CE differential groups 1 and 9 contain more often successful mergers.

Third, we find that the medium- and long-term effects differ markedly from those of the short-run. On the one hand, mergers which involve acquirers with CE levels on average 10 percentage points higher than those of the target are less frequently identified as a success. On the other hand, those transactions where the target is around 5 to 7 percentage points more cost efficient than the acquirer are also in the medium-run more often a success. However, for this group the benefits from transferring cost management skills wear off at the latest six years after the merger according to our results. Moreover, in the medium- and longterm those groups containing mergers with differentials closest to the average, i.e. groups 5 to 7 , contain successful mergers more frequently than any of the extreme differential merger groups.

In sum, we conclude that large pre-merger CE differentials yield more frequently successful mergers in the immediate aftermath of the transaction. But these short-term improvements in $\mathrm{CE}$, which can be due to a transfer of skill, wear off already in the medium run. Three or more years after a transaction, mergers involving banks with pre-merger $\mathrm{CE}$ differentials between zero and one percentage point yield more often successful transactions.

\subsection{Distressed Mergers}

We next assess if distressed mergers are represented more than proportionately in one of our merger categories. To this end we examine the short-, mediumand long-term categorisation of (distressed) mergers in table 11. We compare group representations of mergers without regulatory attention versus those where the Bundesbank identified either the target, the acquirer or both institutes as distressed.

Approximately 7 percent of all transactions are distressed. We discuss three major conclusions with respect to the success of distressed mergers. First, the distribution of distressed mergers roughly mimics the one for non-distressed transactions. This indicates that a number of non-distressed mergers may be rather similar to those that received regulatory attention. With respect to the group of mergers where both acquirer and target received regulatory attention we note that robust inference seems inappropriate due to the very low sample size. We therefore disregard this group in this comparison.

Second, mergers where the target is distressed are more often a success than transactions where the acquirer is distressed. This result holds for the short, the 
Table 11: Distribution of distressed mergers across groups

\begin{tabular}{|c|c|c|c|c|c|c|}
\hline Years & Group & \multicolumn{4}{|c|}{ Distressed ... } & Total \\
\hline One & & None & Target & Acquirer & Both & $N$ \\
\hline & $\overline{\mathrm{I}}$ & $48 \%$ & $50 \%$ & $46 \%$ & $0 \%$ & $48 \%$ \\
\hline & II & $28 \%$ & $32 \%$ & $24 \%$ & $50 \%$ & $28 \%$ \\
\hline & III & $16 \%$ & $5 \%$ & $22 \%$ & $25 \%$ & $16 \%$ \\
\hline & IV & $8 \%$ & $13 \%$ & $7 \%$ & $25 \%$ & $8 \%$ \\
\hline & Total N & 1,044 & 38 & 41 & 4 & 1,127 \\
\hline Three & & & & & & \\
\hline & $\overline{\mathrm{I}}$ & $50 \%$ & $58 \%$ & $42 \%$ & $67 \%$ & $48 \%$ \\
\hline & II & $19 \%$ & $17 \%$ & $25 \%$ & $33 \%$ & $21 \%$ \\
\hline & III & $23 \%$ & $21 \%$ & $21 \%$ & $0 \%$ & $25 \%$ \\
\hline & IV & $8 \%$ & $4 \%$ & $13 \%$ & $0 \%$ & $6 \%$ \\
\hline & Total N & 626 & 24 & 24 & 3 & 677 \\
\hline Six & & & & & & \\
\hline & $\mathrm{I}$ & $56 \%$ & $50 \%$ & $43 \%$ & $100 \%$ & $53 \%$ \\
\hline & II & $14 \%$ & $50 \%$ & $14 \%$ & $0 \%$ & $17 \%$ \\
\hline & III & $26 \%$ & $0 \%$ & $43 \%$ & $0 \%$ & $26 \%$ \\
\hline & IV & $4 \%$ & $0 \%$ & $0 \%$ & $0 \%$ & $5 \%$ \\
\hline & Total N & 189 & 2 & 7 & 2 & 200 \\
\hline
\end{tabular}

Note: Each bank treated separately after merger;

including multiple acquirers once.

medium and the long run. Overall, the results clearly indicate that rendering a distressed bank the acquirer in a problem merger is not beneficial from a $\mathrm{CE}$ perspective.

Third, we note that according to table 4, the majority of distressed mergers occurred after 1997. Thus, our comparison of distressed and non-distressed mergers six years after the transaction suffers from a lack of observations because the last year of available data is 2003. We thus caution to draw inferences based on these results alone. However, one interesting outcome is that out of the eleven mergers that are still in existence six years after the transaction, the majority of seven are transactions where the acquirer was initially distressed. Moreover, these mergers are identified relatively often in group III. We tentatively interpret this as a further indication that mergers with distressed acquirers are not recommended.

In sum we conclude that mergers can be a successful tool to alleviate distress in the medium run. However, short-run gains are unlikely to materialise and wear off in the long run. It is more favourable to render distressed banks the target rather than the acquirer from an efficiency point of view. This also reduces the risk of a merged institute failing to match both the peer groups level and change of CE, i.e. a group III merger.

\subsection{Regional Proximity}

We turn next to the question if regional proximity results in relatively more successful mergers. In table 12 we compare the distribution of transactions across groups depicting three different degrees of regional proximity. First, we depict mergers where both the acquirer and the target are from the same county. Second, we depict mergers where partners are from the next lower level of regional demar- 
cation available, namely municipalities. In the third pair of columns we show those mergers where partners are from different regions as a reference group. As previously, we analyse the short, medium and long run. We focus in our discussion on three major conclusions.

First, merging savings banks that are located close to each other are relatively infrequently identified as successful mergers in the short run. The frequency of group I mergers outside the county is 46 percent and compares to 42 percent of successful county mergers and to only 38 percent of successful municipality mergers. We conclude that in the short run regional proximity hampers merger success for this banking group. If the choice of a partner from the same municipality reflects a limited freedom to search for a partner, our results imply that relaxing regulation on regional limitations is beneficial from a $\mathrm{CE}$ point of view. Note, however, that we cannot observe whether these merger partners voluntarily decide to join or if they were forced to join forces with "available" banks within their region.

Table 12: Successful mergers and regional proximity

\begin{tabular}{|c|c|c|c|c|c|c|c|}
\hline Years & Group & \multicolumn{2}{|c|}{ County } & \multicolumn{2}{|c|}{ Municipality } & \multicolumn{2}{|c|}{ Other } \\
\hline One & & Savings & Coop's & Savings & Coop's & Savings & Coop's \\
\hline & $\mathrm{I}$ & $42 \%$ & $49 \%$ & $38 \%$ & $48 \%$ & $46 \%$ & $51 \%$ \\
\hline & II & $24 \%$ & $29 \%$ & $38 \%$ & $28 \%$ & $22 \%$ & $27 \%$ \\
\hline & III & $20 \%$ & $16 \%$ & $8 \%$ & $15 \%$ & $15 \%$ & $16 \%$ \\
\hline & IV & $14 \%$ & $7 \%$ & $17 \%$ & $8 \%$ & $17 \%$ & $7 \%$ \\
\hline & Total N & 71 & 554 & 24 & 240 & 44 & 194 \\
\hline \multicolumn{8}{|l|}{ Three } \\
\hline & $\mathrm{I}$ & $47 \%$ & $51 \%$ & $35 \%$ & $48 \%$ & $43 \%$ & $42 \%$ \\
\hline & II & $17 \%$ & $22 \%$ & $15 \%$ & $21 \%$ & $9 \%$ & $27 \%$ \\
\hline & III & $23 \%$ & $23 \%$ & $35 \%$ & $28 \%$ & $30 \%$ & $23 \%$ \\
\hline & IV & $13 \%$ & $5 \%$ & $15 \%$ & $4 \%$ & $17 \%$ & $9 \%$ \\
\hline & Total N & 53 & 330 & 20 & 149 & 25 & 100 \\
\hline \multicolumn{8}{|l|}{ Six } \\
\hline & $\overline{\mathrm{I}}$ & $64 \%$ & $48 \%$ & $54 \%$ & $56 \%$ & $50 \%$ & $50 \%$ \\
\hline & II & $14 \%$ & $25 \%$ & $0 \%$ & $15 \%$ & $6 \%$ & $19 \%$ \\
\hline & III & $17 \%$ & $23 \%$ & $46 \%$ & $28 \%$ & $25 \%$ & $31 \%$ \\
\hline & IV & $6 \%$ & $4 \%$ & $0 \%$ & $0 \%$ & $19 \%$ & $0 \%$ \\
\hline & Total N & 36 & 77 & 13 & 39 & 18 & 18 \\
\hline
\end{tabular}

Note: Each bank treated separately after merger; including multiple acquirers once.

Second, the detrimental effects of regional proximity on savings banks mergers vanish over time as both county and municipality mergers are now more often a success compared to those savings bank mergers involving partners from outside the region. Note, however, that the gap between frequencies of group I mergers between county and municipality widens. Moreover, the number of clearly failed mergers, group III, is the highest for municipality mergers among savings banks. Together these two issues suggest that some proximity is fine, at least in the long run. But being too close is significantly less beneficial.

Third, this result does not hold for cooperative bank mergers. In the short run the representation of county and municipality mergers in group I is just slightly below that for non-regional mergers in table 12 . In fact, in the medium and long run regionally close partners accomplish merger success more frequently compared 
to those outside the region. The closer the partners in a cooperative merger are, the higher are the chances to outperform non-merging banks in terms of CE level and change even up to six years after the merger. This result is in line with Lang and Welzel (1999), who note that successful cooperative bank mergers in Bavaria are those that, first, involve partners with some overlap in their branch networks and, second, reduce these redundancies by closing branches in order to enhance efficiency. In the same vein, we showed in part ?? of this thesis that the number of cooperatives is despite ongoing consolidation still the highest in Germany, while the size of their operations continues to be small. Our results here indicate that cooperative bank mergers might thus have eliminated some of the excess coverage in regions where fewer banks can provide customers more efficiently with banking services. While we note that we have no information on branching overlap and (lack of) branch closure, the results indicate to us that mergers of regionally close cooperative banks are different from savings bank mergers. As opposed to the former, proximity may not reflect regulatory limitations but rather the elimination of too dense banking (and branching) networks.

In sum, we find that regional proximity has different effects on mergers among savings and cooperative banks, respectively. With the exception of county mergers in the long run, savings banks are less frequently represented in group I compared to cooperative banks. While the frequency of successful savings bank mergers increases in the long run, we also note the number of group III mergers among savings increases over time if both partners are regionally closest. In contrast, regional proximity among cooperative banks implies higher chances of a successful merger. The different results may reflect that regional proximity among savings bank mergers is more due to restrictive regulation, and thus the absence of adequate partners, while it represents for cooperative bank mergers an appropriate tool to cut down excess capacities in local markets.

\subsection{Learning}

We hypothesised in section 3.4 that turning a merger into a success depends on two potentially off-setting factors. On the one hand, a merger can benefit from the experience a management team obtained during previous transactions. On the other hand, positive effects of the merger can be subject to insurmountable complexity when integrating operations of multiple targets acquired at the same time.

To this end we distinguish four different types of mergers introduced in section 3.4. These are labelled "Single", "Multiple", "Both" and "Serial" in table 13 and we briefly recapitulate the respective definitions for the ease of discussion here. The first group comprises those mergers which constitute the first deal of a bank and involve exactly one target. The second group includes mergers which constitute the first transaction of the acquirer and involve more than one target at the same time. The third group includes those mergers where the acquiring institute conducts its second (or higher) deal and absorbed more than one target. Finally, the fourth group comprises mergers where the acquirers conduct its second (or higher) deal but absorbed in each transaction one target only. To sum, the two dimensions according to which we categorise are, first, the number of the deal 
conducted and, second, the number of targets per deal. ${ }^{44}$ Three results depicted in table 13 are particularly noteworthy.

First, the results for Serial mergers confirm that benefits from learning prevail. Those transactions where the acquirer already absorbed one other bank previously yield especially in the short run significantly more often a success. Note, however, that the advantages associated with experience in conducting a merger wear-off in the medium run. After three years the relative frequency is slightly below the population average. The rebounce of relatively many group I mergers six years after the merger does not allow further inference as again the sample size of seven is too small. We conclude that having conducted previous acquisitions facilitates above benchmark CE performance immediately after the transaction. However, in subsequent years it seems that experience can no longer facilitate above average CE levels and changes.

Table 13: Learning benefits versus integration hazards

\begin{tabular}{|c|c|c|c|c|c|c|}
\hline Years & Group & \multicolumn{3}{|c|}{ Acquirer type } & \multicolumn{2}{|r|}{ Total } \\
\hline One & & Single & Multiple & Both & Serial & $N$ \\
\hline & $\mathrm{I}$ & $46 \%$ & $53 \%$ & $27 \%$ & $58 \%$ & $48 \%$ \\
\hline & II & $28 \%$ & $22 \%$ & $49 \%$ & $28 \%$ & $28 \%$ \\
\hline & III & $17 \%$ & $14 \%$ & $19 \%$ & $11 \%$ & $16 \%$ \\
\hline & IV & $9 \%$ & $12 \%$ & $5 \%$ & $4 \%$ & $8 \%$ \\
\hline & Total N & 738 & 93 & 37 & 259 & 1,127 \\
\hline \multicolumn{7}{|l|}{ Three } \\
\hline & $\bar{I}$ & $47 \%$ & $56 \%$ & $40 \%$ & $45 \%$ & $48 \%$ \\
\hline & II & $22 \%$ & $11 \%$ & $33 \%$ & $22 \%$ & $21 \%$ \\
\hline & III & $24 \%$ & $23 \%$ & $27 \%$ & $30 \%$ & $25 \%$ \\
\hline & IV & $7 \%$ & $10 \%$ & $0 \%$ & $3 \%$ & $6 \%$ \\
\hline & Total N & 504 & 62 & 15 & 96 & 677 \\
\hline \multicolumn{7}{|l|}{ Six } \\
\hline & $\mathrm{I}$ & $53 \%$ & $48 \%$ & $50 \%$ & $71 \%$ & $53 \%$ \\
\hline & II & $17 \%$ & $13 \%$ & $50 \%$ & $29 \%$ & $17 \%$ \\
\hline & III & $26 \%$ & $30 \%$ & $0 \%$ & $0 \%$ & $26 \%$ \\
\hline & IV & $4 \%$ & $9 \%$ & $0 \%$ & $0 \%$ & $5 \%$ \\
\hline & Total N & 168 & 23 & 2 & 7 & 200 \\
\hline
\end{tabular}

In contrast, our second result highlights that those banks that acquired more than one target during their first acquisition, i.e. Multiple, do on average not suffer from prohibitively high integration hazards. In fact, they exhibit just as the Serial group a higher frequency of group I mergers compared to both the population and Single mergers. In fact, they do so for both the short and the medium run. This suggests that it is preferable from an efficiency point of view that if a bank wants to acquire more than one target, that it does so within the same year rather than engaging in a series of single and subsequent acquisitions.

\footnotetext{
${ }^{44}$ Note, that we allow one single institute to fall into multiple categories of mergers in the course of time. For example, each banks' first merger is by definition a single merger. But some banks engaging in single mergers might subsequently enter multiple, serial or both types of deals. We choose this approach to learn how different types of transaction affected the further development of efficiency of the merged unit.
} 
A possible explanation for the superiority of Multiple over Serial mergers are scale economies regarding integration costs. For example, it might be cheaper to integrate two different accounting systems into the acquirer's reporting systems during one single SAP project rather than having to rely continuously on external consultants for two subsequent mergers.

Our final conclusion refers to the group of Both. These types of deals always suffer from significantly fewer successful mergers. While we are aware that the low number of observations throughout all years requires cautious interpretation, we note that these results are stable across all post merger year cohorts. Therefore, we tentatively conclude that transactions involving multiple targets after having conducted other acquisitions beforehand is not beneficial from a $\mathrm{CE}$ perspective. A first potential explanation is that a bank might simply overestimate its abilities to conduct the merger while not having finished yet the integration of the previous target. Then, the hazards can become prohibitively difficult to manage, ultimately leading to poor performance. Importantly, our results indicate that such problems might stick around even in the long run.

In sum, we conclude that successful mergers are facilitated to some extent by learning effects. Serial acquirers enjoy relatively more often superior performance in most time periods after a merger than Single mergers. Post-merger integration problems are less of a problem if no other mergers occurred previously as exhibited by many group I mergers for Multiple acquirers. Conversely, multiple targets pose a problem if other acquisitions have been conducted before. We interpret this finding as to imply that starting a new integration process just after, or potentially even while still being involved in an ongoing one, results relatively more often in failure of the merger to result in efficiency gains.

\section{Conclusion}

In this paper, we suggest a taxonomy as how to evaluate the merger wave of German savings and cooperative banks. We employ cost efficiency (CE) estimates obtained with stochastic frontier analysis to benchmark banks on the basis of their ability to efficiently convert inputs into outputs.

We define successful mergers as those which, first, yield CE levels that are above mean $\mathrm{CE}$ of non-merging banks and, second, exhibit larger changes between the evaluation and merger years as compared to the respective cohort of nonmerging banks in the same period.

Our results indicate that approximately every second merger is a success according to our taxonomy. On average, cooperative bank mergers are more often a success than savings bank mergers. Importantly, the margin of success as indicated by mean CE level differences between merging and non-merging banks is very small - on the order of one to two percentage points only.

Successful mergers exhibit higher profitability than transactions resulting in below benchmark levels of CE, i.e. groups II and III. However, we find for both banking groups that mergers in group III, i.e. those that exhibit the highest change in CE but below benchmark CE levels, also exhibit high profitability. For savings banks, we find that both concentration and net interest margins are highest for group III, too. We interpret these findings as indication that savings 
bank transactions might fail to yield efficiency improvements due to the absence of market discipline. In contrast, we find for cooperative banks that mean concentration and net interest margins remain similar across groups. Consequently, market power concerns do not seem to be an issue for cooperative bank mergers.

Investigation of four particularities of the German bank merger wave lead us to the following four core conclusions. First, the potential for transferring skills from acquirers and targets is low as mean pre-merger CE differentials are minuscule. Those few transactions with high CE differentials do not result in sustained efficiency gains. Instead, we find that particularly successful mergers exhibit mean differentials between zero and one percentage point of $\mathrm{CE}$.

Second, bank mergers where the acquirer is distressed are less often a success. In contrast, mergers involving distressed targets lead in the short and medium run relatively more often to successful mergers. Therefore, mergers where the less efficient institute is the target are preferable.

Third, regional proximity of merger partners due to the principle of regional demarcation has on balance detrimental CE effects for savings banks but positive $\mathrm{CE}$ effects for cooperative banks. Cooperative bank mergers involving banks from the same municipality are in the medium and long run more often a success than those among banks from the same county or outside the same region. Only savings bank mergers of partners from the same county are in the medium and long run more often a success. But savings bank mergers involving partners from the same municipality are rarely a success and more often an outright failure. This suggests that a further investigation of the costs and benefits of regulation limiting the choice of partners in a consolidating environment is warranted.

Fourth, we find that a substantial number of acquirers absorb more than one institute during each deal and/or over the whole time period investigated. For the short and medium run our results favour those transactions where acquirers absorbed more than one bank, so-called multiple acquirers. However, those banks that acquire more than one institute after having already absorbed another bank previously lead less often to successful mergers. Thus, we conclude that approval of follow-up mergers should also be based on past acquisition activities.

This study provides important first time evidence on two major banking pillars in Germany's bank-based system. Nevertheless, a number of caveats and leads for further research should be noted. First, we do not attempt here to empirically estimate the determinants of why a particular merger is identified as a success or not. Future research along the lines of limited dependent analysis is therefore certainly fruitful. Second, we do not attempt to explicitly model as to what explains the transition of single banks after a merger from one category into another. Markov chain inspired modelling might be an interesting extension of this study. Finally, many academics and practitioners argue that mergers are motivated by profit rather than cost considerations. Hence, a natural complement to the assessment conducted here would include profit efficiency. 


\section{References}

Altunbas, Y., L. Evans, and P. Molyneux (2001, November). Bank ownership and efficiency. Journal of Money, Credit, and Banking 33(4), 926-54.

Altunbas, Y. and P. Molyneux (1996). Economies of Scale and Scope in European Banking. Applied Financial Economics 6(4), 655-672.

Amel, D., C. Barnes, F. Panetta, and C. Salleo (2004, October). Consolidation and Efficiency in the Financial Sector: A Review of the International Evidence. Journal of Banking \&6 Finance 28(10), 2493-2519.

Berger, A. N. (2003). The Efficiency Effects of a Single Market for Financial Services in Europe. Journal of Operational Research 150, 466-481.

Bikker, J. A. and K. Haaf (2002, November). Competition, concentration and their relationship: An empirical analysis of the banking industry. Journal of Banking \&5 Finance 26(11), 2191-2214.

Bos, J. W. B., F. Heid, J. W. Kolari, M. Koetter, and C. J. M. Kool (2004). The Stability and Sensitivity of Stochastic Frontier Efficiency Scores When Controlling for Heterogeneity. mimeo.

Bos, J. W. B. and J. W. Kolari (2003, July). Large Bank Efficiency in Europe and the United States: Are There Economic Motivations for Geographic Expansion in Financial Services? DNB Research Series Supervision 61.

Greene, W. H. (2002, October). Fixed and Random Effects in Stochastic Frontier Models. Working Paper Stern School of Business.

Hackethal, A. (2004). German banks and banking structure. In J. Krahnen and R. Schmidt (Eds.), The German Financial System, pp. 387-424. Oxford: Oxford University Press.

Hempell, H. S. (2004). Testing for Competition Among German Banks. Deutsche Bundesbank Discussion Paper Series 1 (04/02), 1-47.

Koetter, M., J. W. B. Bos, F. Heid, J. W. Kolari, C. J. M. Kool, and D. Porath (2004). Accounting for Distress when Predicting Bank Mergers. mimeo.

Lang, G. and P. Welzel (1996, July). Efficiency and technical progress in banking: Empirical results for a panel of german cooperative banks. Journal of Banking and Finance 20(6), 1003-23.

Lang, G. and P. Welzel (1998, July). Technology and cost efficiency in universal banking a "thick frontier"-analysis of the german banking industry. Journal of Productivity Analysis 10(1), 63-84.

Lang, G. and P. Welzel (1999). Mergers Among German Cooperative Banks: A Panel-Based Stochastic Frontier Analysis. Small Business Economics 13(4), 273-86.

Maselli, A. (2000). Unternehmensfinanzierung, Kapitalmarktunterschiede und Regulierungspraxis: Vergleichende Analyse Für Deutschland und Die USA. Berlin. Deutscher Sparkassen und Giroverband.

OECD (2000). Mergers in Financial Services. Paris: OECD. 
Peristiani, S. (1997). Do Mergers Improve the X-Efficiency and Scale Efficiency of U.S. Banks? Evidence from the 80s. Journal of Money, Credit, and Banking 29(3), 326-337.

Porath, D. (2004). Estimating Probabilities of Default for German Savings Banks and Credit Cooperatives. Discussion Paper Series 2: Banking and Financial Supervision 6, 1-32.

Reifner, U. and J. Evers (1998). The Social Responsibility of Credit Institutions in the EU: Access, Regulation and New Products. In Schriften des Institut für Finanzdienstleistungen e.V., Baaden Baaden. Nomos.

Robertson, D. D. (2001). A Markov View of Bank Consolidation: 1960-2000. Economic and Policy Analysis Working Paper 4.

Schenk, H. (2000). On the Performance of Banking Mergers. Some Propositions and Policy Implications. In The Impact of Mergers and Acquisitions in Finance on Workers, Consumers and Shareholders, Brussels/Geneva, pp. 24-43. UNI-Europa.

Sealey, C. W. and J. T. Lindley (1977, September). Inputs, Outputs, and a Theory of Production and Cost and Depository Financial Institutions. The Journal of Finance 32(4), 1251-1265.

Valverde, S. C., D. B. Humphrey, and R. L. Del Paso (2004). Electronic Payments and ATMs: Changing Technology and Cost Efficiency in Banking. 25th SUERF Colloquium Volume.

Vander Vennet, R. (1996). The Effects of Mergers and Acquisitions on the Efficiency and Profitability of E.C. Credit Institutions. Journal of Banking E Finance 20, 1531-1558. 